\title{
Comparison of Mechanisms for Low-Frequency Variability of Summer Arctic Sea Ice in Three Coupled Models
}

\author{
DAWEI LI \\ Program in Atmospheric and Oceanic Sciences, Princeton University, Princeton, New Jersey \\ RONG ZHANG AND THOMAS KNUTSON \\ NOAA/Geophysical Fluid Dynamics Laboratory, Princeton, New Jersey
}

(Manuscript received 19 August 2016, in final form 18 October 2017)

\begin{abstract}
In this study the mechanisms for low-frequency variability of summer Arctic sea ice are analyzed using long control simulations from three coupled models (GFDL CM2.1, GFDL CM3, and NCAR CESM). Despite different Arctic sea ice mean states, there are many robust features in the response of low-frequency summer Arctic sea ice variability to the three key predictors (Atlantic and Pacific oceanic heat transport into the Arctic and the Arctic dipole) across all three models. In all three models, an enhanced Atlantic (Pacific) heat transport into the Arctic induces summer Arctic sea ice decline and surface warming, especially over the Atlantic (Pacific) sector of the Arctic. A positive phase of the Arctic dipole induces summer Arctic sea ice decline and surface warming on the Pacific side, and opposite changes on the Atlantic side. There is robust Bjerknes compensation at low frequency, so the northward atmospheric heat transport provides a negative feedback to summer Arctic sea ice variations. The influence of the Arctic dipole on summer Arctic sea ice extent is more (less) effective in simulations with less (excessive) climatological summer sea ice in the Atlantic sector. The response of Arctic sea ice thickness to the three key predictors is stronger in models that have thicker climatological Arctic sea ice.
\end{abstract}

\section{Introduction}

The rapid shrinking of summer Arctic sea ice extent (SIE) over the satellite era signals a dramatic change in the cryosphere (Comiso et al. 2008). This observed rapid Arctic sea ice decline is also found to be the leading cause in the observed amplified Arctic surface warming over the last several decades (Serreze et al. 2009; Screen and Simmonds 2010). If the observed rapid decline trend of September Arctic SIE were to continue, then the summer Arctic Ocean would become nearly ice free within the next decade (Overland and Wang 2013). This projection is much sooner than that simulated by most models from phase 5 of the Coupled Model Intercomparison Project (CMIP5) under increased anthropogenic radiative forcing (Stroeve et al. 2012; Massonnet et al. 2012). In addition, the CMIP5 multimodel mean forced response shows stronger warming in global mean surface temperature but a much slower decline in summer Arctic SIE than that observed over the period

Corresponding author: Dawei Li, daweil@princeton.edu
2001-12 (Zhang and Knutson 2013). This pair of observed-model discrepancies strongly suggests that anthropogenic radiative forcing might not be the sole dominant cause for the observed Arctic sea ice decline.

Previous studies identified various physical processes at interannual-decadal time scales that might be important for the observed summer Arctic sea ice decline, such as the positive ice-infrared feedback (Francis and Hunter 2006; Deser and Teng 2008) and the ice-albedo feedback (Winton 2006; Perovich et al. 2008; Steele et al. 2010), warming of the Atlantic Water in the Arctic (Zhang et al. 1998; Polyakov et al. 2010; Alexeev et al. 2013), increased Pacific inflow through the Bering Strait (Shimada et al. 2006; Woodgate et al. 2012), and the interaction between the Arctic dipole and transpolar ice drift (Wu et al. 2006; Wang et al. 2009; Overland and Wang 2010; Overland et al. 2012; Wettstein and Deser 2014).

Long historical and paleoproxy records indicate pronounced fluctuations in the Arctic climate at multidecadal-centennial time scales. For example, multidecadal variability has been recorded in the Arctic 
surface air temperature (SAT), and the amplified Arctic warming during the 1930s appears similar in some ways to the warming during recent decades (Polyakov et al. 2003; Semenov and Bengtsson 2003). Reduced Arctic sea ice associated with the natural variability in the oceanic inflow into the Barents Sea is likely a driver for the early twentieth-century Arctic warming (Bengtsson et al. 2004). A high-resolution multicentury algal proxy for Arctic sea ice cover reveals substantial multidecadal and centennial Arctic sea ice variability (Halfar et al. 2013).

Low-frequency variability of winter Arctic sea ice is found to be anticorrelated with the Atlantic multidecadal variability (AMV) in both climate model simulations (Mahajan et al. 2011; Day et al. 2012) and multicentury historical and paleoproxy records (Miles et al. 2014). The Atlantic meridional overturning circulation (AMOC), which has likely strengthened since the mid-1970s as inferred from its observed subsurface ocean temperature fingerprints (Zhang 2007, 2008), may have led to stronger Atlantic heat transport into the Arctic and contributed to the observed rapid decline of summer Arctic SIE since 1979 (Zhang 2015). Swart et al. (2015) identified a 7-yr period (2007-13) of near-zero trend in the observed Arctic September SIE that is likely linked to natural variability. Natural variability is also found to be important for summer Arctic SIE in models as seen by the variability among individual ensemble members of NCAR CCSM3 and CCSM4 simulations under the same changes in anthropogenic forcing (Holland et al. 2008a; Kay et al. 2011). Winter Arctic sea ice, especially in the Barents Sea, is also strongly influenced by the Atlantic Ocean heat transport. Analysis of CMIP5 coupled model simulations implies that the recent decline in winter SIE over the Barents Sea is strongly related to the strengthening of the Atlantic heat transport ( $\mathrm{Li}$ et al. 2017). If the Atlantic heat transport into the Arctic were to weaken in the near future due to multidecadal natural variability, then we may see a much longer hiatus period in the decline of both winter (Yeager et al. 2015) and summer (Zhang 2015) Arctic SIE.

The apparent inconsistency between the observed rapid declining trend of September Arctic SIE and that in the CMIP5 multimodel ensemble (Zhang and Knutson 2013) might be partially caused by an underestimation of simulated low-frequency summer Arctic sea ice internal variability. Key to a more reliable projection of future changes in summer Arctic sea ice may be a better understanding of the driving mechanisms of the low-frequency summer Arctic sea ice variability. Using a 3600-yr-long control simulation of the Geophysical Fluid Dynamics Laboratory (GFDL) Climate
Model, version 2.1 (CM2.1), Zhang (2015) identified three key predictors for summer Arctic SIE variability at multidecadal-centennial time scales: the Atlantic and Pacific Ocean heat transport into the Arctic and the Arctic dipole in the atmosphere. The observed decline trend in September Arctic SIE could have been partially induced by the low-frequency natural variability associated with the three key physical processes. These results, however, are mainly based upon the analyses from a single climate model (GFDL CM2.1). On the other hand, understanding the role of low-frequency natural variability in the observed summer Arctic SIE decline is quite challenging because of the short observational records over the Arctic region. As a step toward better understanding at this stage, we investigate the mechanisms for low-frequency variability of summer Arctic sea ice in different coupled models to identify the more robust elements across different models.

The predictors identified by Zhang (2015) include both dynamic (Arctic dipole) and thermodynamic (Atlantic and Pacific Ocean heat transport) contributions. Here we apply the same approach to the available long control simulations from three coupled models with different Arctic sea ice mean states to test the robustness of the mechanisms proposed by Zhang (2015). Hence, the focus is on the response of low-frequency summer Arctic sea ice variability to these three key predictors (the Atlantic and Pacific heat transport into the Arctic and the Arctic dipole) and to elucidate the influence of the Arctic sea ice mean states on the response. Section 2 describes the data and methods used in the analysis and the comparison of simulated Arctic sea ice mean states and variability in the three models. Sections 3-7 show the detailed results, including the response of summer Arctic sea ice concentration, extent, thickness, mass, and surface air temperature to the key predictors, and the influence of the Arctic sea ice mean states on the response. Though our work is mainly focused on the influence of the key predictors on summer Arctic sea ice, as in Zhang (2015), we also include some discussion on winter Arctic sea ice mass and SIE responses in sections 5 and 6 . The contributions from each predictor to the observed sea ice decline are discussed in section 8. Conclusions and a discussion on the robustness of the mechanisms for the low-frequency summer Arctic sea ice variability are presented in section 9.

\section{Descriptions of data and methods and simulated Arctic sea ice climatology and variability}

The model data used in this study are 3600-yr segments of the preindustrial control simulations from 
GFDL CM2.1 (Delworth et al. 2006) and the GFDL Climate Model, version 3 (CM3) (Donner et al. 2011; Griffies et al. 2011), and an 1801-yr segment of the preindustrial control simulation from the Community Earth System Model (CESM) Large Ensemble project (Kay et al. 2015) hosted by the National Center for Atmospheric Research (NCAR). Only 1801 years of output are available for the NCAR CESM control simulation, which is configured with the Community Atmosphere Model, version 5 (CAM5), with the carbon cycle model (BGC). The main differences between GFDL CM2.1 and CM3 are in their associated atmospheric models. The atmospheric model used in GFDL CM3 [i.e., the Atmosphere Model, version 3 (AM3)] has a higher vertical resolution in the atmosphere, and a substantially modified dynamical core, aerosol physics, atmospheric chemistry, and convection scheme, compared to the atmospheric model (AM2) used in GFDL CM2.1 (Donner et al. 2011). GFDL CM2.1 and CM3 essentially share the same ocean and sea ice models, except that the dry snow and sea ice albedos in CM3 are higher and more realistic than the corresponding values in CM2.1 (Donner et al. 2011; Griffies et al. 2011).

Since the focus of this study is on the variability at multidecadal and centennial time scales, all model data are 30-yr low-pass filtered (LF) before further analysis. A comparison of the results with those using alternative multidecadal cutoff periods (i.e., 25 or $40 \mathrm{yr}$ ) indicates that our results are not sensitive to the choice of a 30-yr low-pass filter. A "significant correlation" means the $p$ value from a two-tailed test using a $t$ distribution with adjusted effective degrees of freedom is less than 0.01 . Here we use long preindustrial control simulations because most available control simulations under current radiative conditions for the satellite period are not long enough for a study focusing on multidecadal and centennial time-scale variability.

A reference temperature of $0^{\circ} \mathrm{C}$ is used when calculating ocean heat transport. For Atlantic heat transport anomalies, the choice of reference temperature is not important, since the integrated mass budget for the entire Atlantic basin across the Arctic Circle is approximately closed. For the Pacific heat transport across the Arctic Circle, for which the anomalies are dominated by the $\bar{v} T^{\prime}$ term (i.e., advection of the anomalous temperature by the mean flow) in all three models (probably as result of the coarse resolutions in these models), the term $\bar{v} T^{\prime}$ is insensitive to the choice of reference temperature.

The observed Arctic sea ice concentration (SIC) data for the period 1979-2015 are from the National Snow and Ice Data Center (NSIDC) (Cavalieri et al. 1996). For comparison, a much longer SIC dataset reconstructed by Walsh et al. (2017) is used to investigate the centennial time-scale trend and variability of Arctic sea ice. In this study we define the Arctic SIE as the total marine area within the Arctic Circle $\left(66.5^{\circ} \mathrm{N}\right)$ where SIC $\geq 15 \%$. Correspondingly, the climatological sea ice edge is defined as the contour line of $15 \%$ climatological SIC. The Barents Sea SIE is defined as the total marine area where $\mathrm{SIC} \geq 15 \%$ within the Barents Sea region $\left(70^{\circ}-81^{\circ} \mathrm{N}, 15^{\circ}-60^{\circ} \mathrm{E}\right)$.

The observed sea level pressure (SLP) data are from the National Centers for Environmental Prediction (NCEP)-NCAR reanalysis (Kalnay et al. 1996) for the period 1948-2015. The Twentieth Century Reanalysis, version 2 (C20) (Compo et al. 2011), SLP data from the NOAA/Earth System Research Laboratory (ESRL) are also used. The Arctic dipole (AD) index is defined as the principal component (PC) of the second empirical orthogonal function (EOF2) mode of spring [April-July (AMJJ)] SLP anomalies within the Arctic Circle. As shown in previous studies (Wettstein and Deser 2014; Zhang 2015), springtime values are used for exploring the AD's impact on September sea ice because the correlation between AD and September Arctic SIE is strongest for this season.

Figure 1 shows the climatological September SIC simulated by the three coupled models, along with the observed climatology (from NSIDC) over the satellite period. Compared with the recent observed climatology, the simulated September SIC in GFDL CM2.1 is lower, while the simulated September SIC in NCAR CESM is excessive in general, especially in the Atlantic sector. The simulated September SIC in GFDL CM3 lies in between GFDL CM2.1 and NCAR CESM, and overall, of the three models, looks most similar to the observations. All three preindustrial control runs simulate higher SIC in the central Arctic close to the North Pole than the recently observed regardless of the overall SIE being larger or smaller than that observed. Note that the purpose of this comparison with the satellite observations is not to provide a strict evaluation of the models' skills in simulating the climatology, as the long control simulations from the three models are under constant preindustrial radiative conditions. Rather, our main purpose here is to understand the observed summer Arctic sea ice decline over the satellite period from the perspective of low-frequency variability and how the mechanisms causing the low-frequency variability of summer Arctic sea ice are affected by the Arctic sea ice mean states.

More pronounced differences among the models are found in their simulated climatological sea ice mass 


\section{September Sea Ice Concentration}

(a) GFDL CM2.1

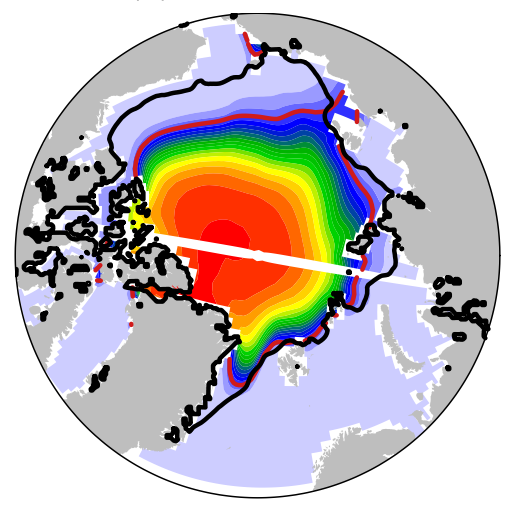

(c) NCAR CESM

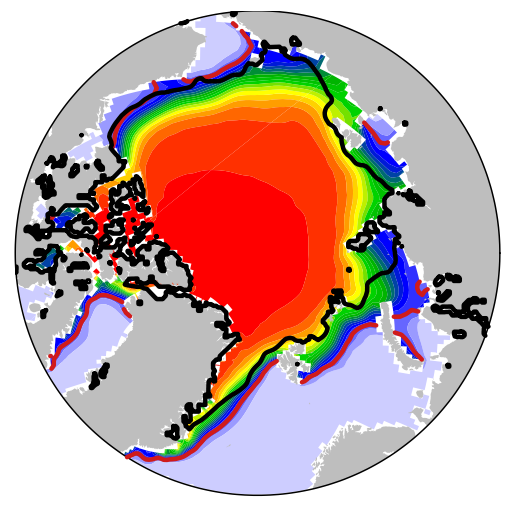

(b) GFDL CM3

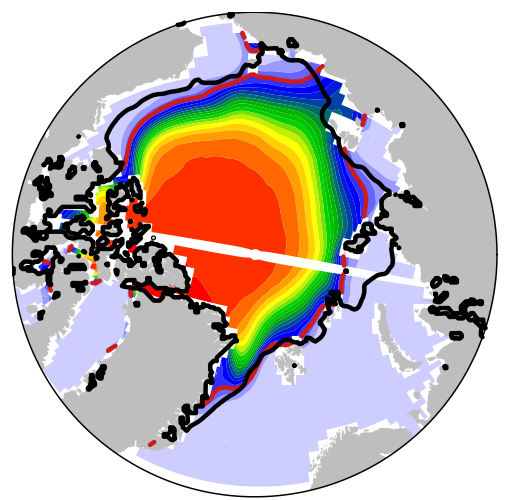

(d) NSIDC

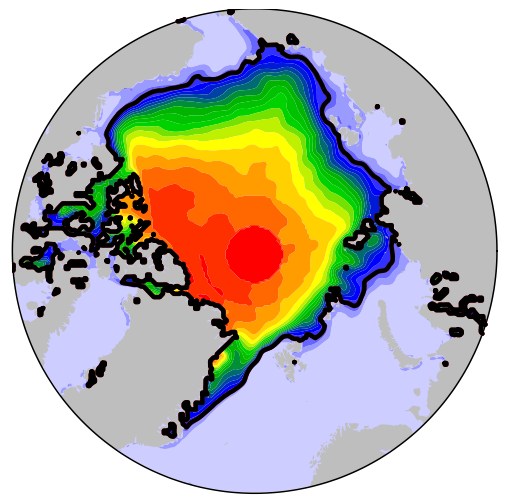

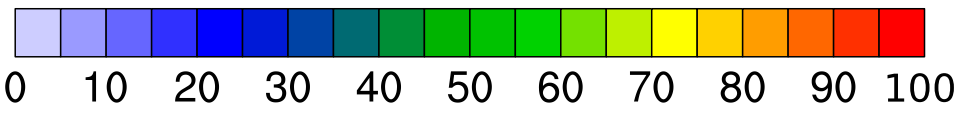

$(\%)$

FIG. 1. Comparison of climatological September SIC (\%). Modeling results are from control runs of (a) GFDL CM2.1, (b) GFDL CM3, (c) NCAR CESM, and (d) observed climatological September Arctic SIC over 1979-2015 (from NSIDC). The black lines mark the positions of the observed climatological September sea ice edge (where SIC drops to $15 \%$ ), and the red lines show the simulated climatological September sea ice edge in each model. The white lines in (a) and (b) are due to the polar projection of SIC simulated on tripolar grids in GFDL models.

(SIM), which by definition is the mass of sea ice per unit area and thus depends on both SIC and sea ice thickness (SIT). The simulated climatological September Arctic SIM is lowest in GFDL CM2.1 and greatest in NCAR CESM, with GFDL CM3 in between (Fig. 2, left). The spatial patterns of the simulated climatological SIT of the three models are similar to those of their respective simulated climatological SIM, with the thinnest sea ice in GFDL CM2.1 and the thickest sea ice in NCAR CSEM among the three models (not shown). Despite its very small summer Arctic sea ice cover, GFDL CM2.1 has a very strong seasonal cycle of Arctic SIE (Donner et al. 2011) with excessive winter Arctic sea ice cover (Fig. 2). The annual mean Arctic SIE of GFDL CM2.1 is comparable to that of NCAR CESM, though the ice is much thinner in GFDL CM2.1 (Fig. 2, right).

Figure 3 shows the standard deviations of September SIC in the three models and observations, and Fig. 4 compares the standard deviations of 30-yr LF September SIC in the three models. The relationship between sea ice low-frequency variability and the mean state is not monotonic; that is, the model with the intermediate 


\section{September and Annual Mean Sea Ice Mass}

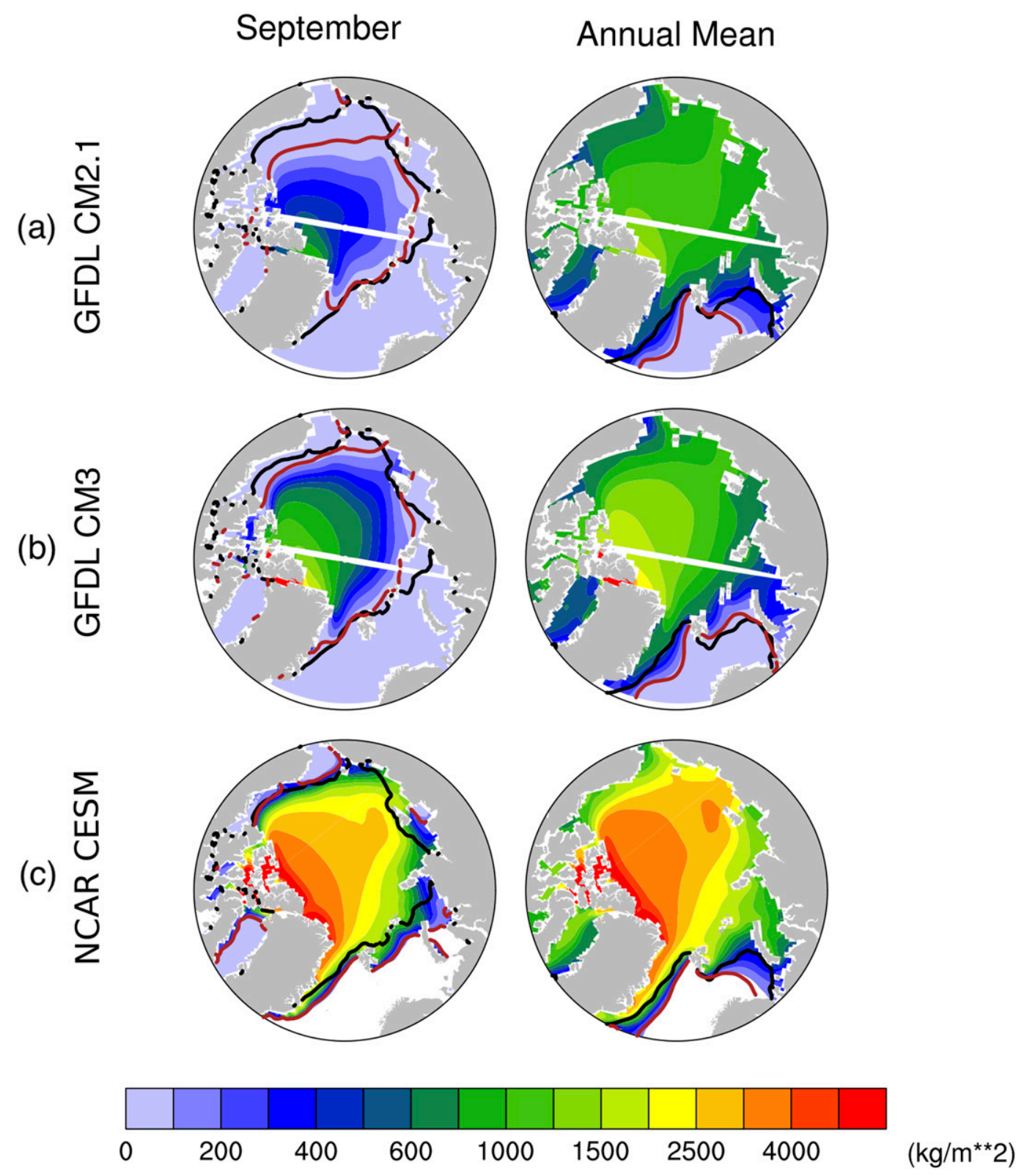

FIG. 2. Comparison of simulated (left) climatological September and (right) annual mean Arctic SIM ( $\mathrm{kg} \mathrm{m}^{-2}$ ). Results are from (a) GFDL CM2.1, (b) GFDL CM3, and (c) NCAR CESM preindustrial control runs. The black lines mark the positions of observed climatological September and annual mean sea ice edge (where SIC drops to $15 \%$ ), and the red lines show the simulated climatological September and annual mean sea ice edge in each model's preindustrial control run. The white lines in (a) and (b) are due to the polar projection of SIC simulated on tripolar grids in GFDL models.

mean state sea ice (GFDL CM3) has the largest lowfrequency variability in September SIC, while both the model with the least mean state sea ice (GFDL CM2.1) and the model with the most mean state sea ice (NCAR
CESM) have smaller low-frequency variability in September SIC (Fig. 4). This indicates that there is not a simple relationship between climatological sea ice thickness and the relative level of low-frequency 
(a) GFDL CM2.1

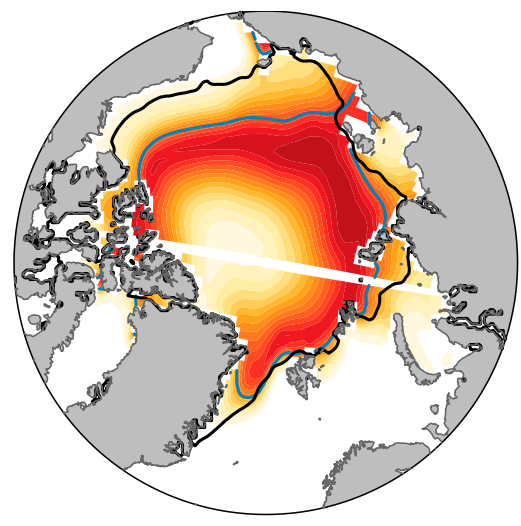

(b) GFDL CM3

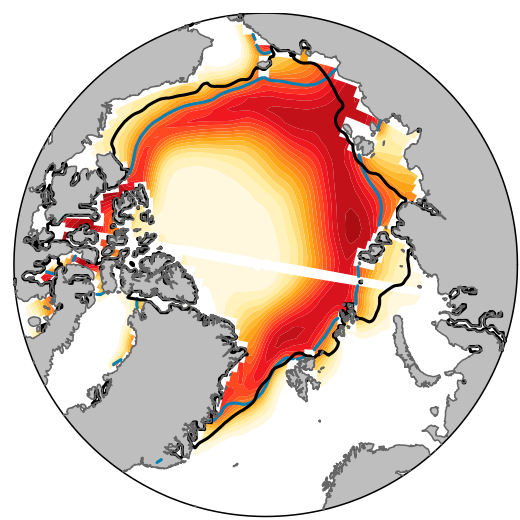

(c) NCAR CESM

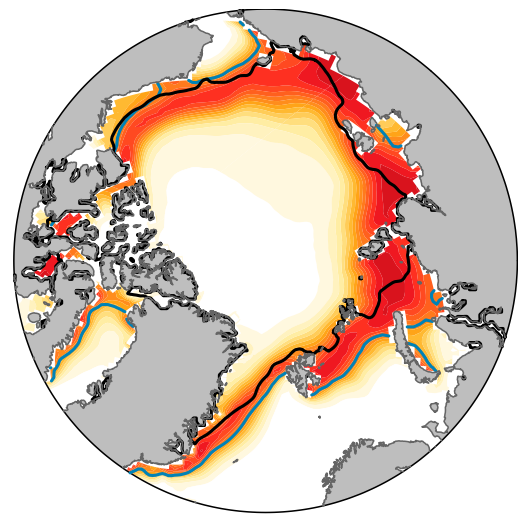

(d) Walsh data

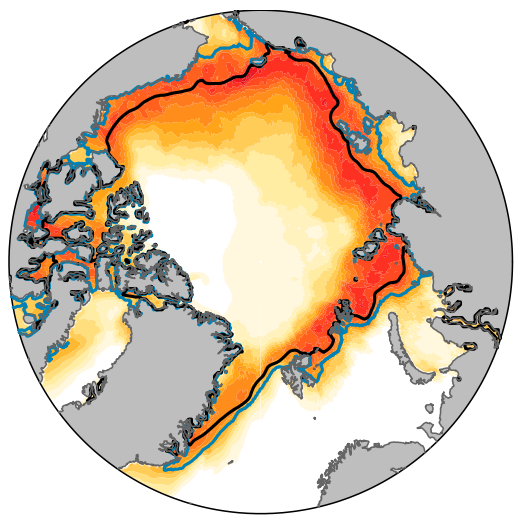

(e) NSIDC

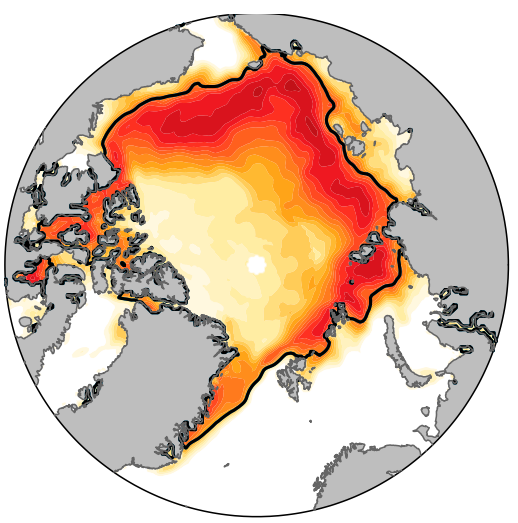

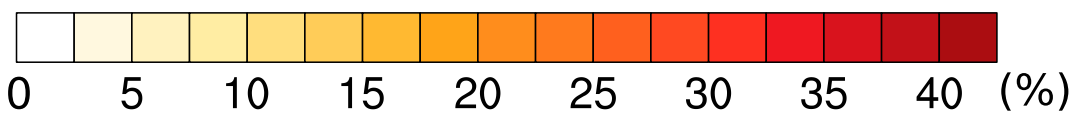

FIG. 3. Comparison of simulated September Arctic SIC SD (\%). Modeling results are from (a) GFDL CM2.1, (b) GFDL CM3, (c) NCAR CESM, (d) reconstructed September Arctic SIC SD over 1850-2014 [data from Walsh et al. (2017)], and (e) observed September Arctic SIC SD over 1979-2015 (from NSIDC). The long-term trend over 1850-2014 has been removed from the Walsh SIC data before the calculation of the SD in (d). The black lines mark the positions of the observed climatological September sea ice edge (where SIC drops to $15 \%$ ), and the blue lines show the simulated climatological September sea ice edge in each model. The white lines in (a) and (b) are due to the polar projection of SIC simulated on tripolar grids in GFDL models.

variability of SIC across these three models, as will be discussed more fully in section 5 .

\section{Multiple regression model for low-frequency variability of September Arctic sea ice extent}

In this study we aim to investigate the response of lowfrequency summer Arctic sea ice variability to the three previously identified key predictors (Zhang 2015), that is, annual mean northward Atlantic heat transport $\left(\mathrm{HT}_{\mathrm{ATL}}\right)$ and Pacific heat transport $\left(\mathrm{HT}_{\mathrm{PAC}}\right)$ across the Arctic Circle and the $\mathrm{AD}$, as well as the influence of the Arctic sea ice mean states on the response. As discussed in Zhang (2015), the predictors are selected from various thermodynamic and wind forcings over the Arctic that have direct impacts on Arctic sea ice. An alternative wind forcing predictor (i.e., the first mode of Arctic SLP or the Arctic Oscillation) does not have much direct impact on September Arctic sea ice low-frequency variability in the models and thus is not used as a predictor. An alternative thermodynamic forcing predictor would be the net upward surface heat flux $F_{\mathrm{SFC}}$ averaged over the Arctic domain; this is strongly correlated with the Atlantic heat transport into the Arctic (discussed in section 7) and thus provides a negative feedback on sea ice changes and is not used as a predictor. 
(a) GFDL CM2.1

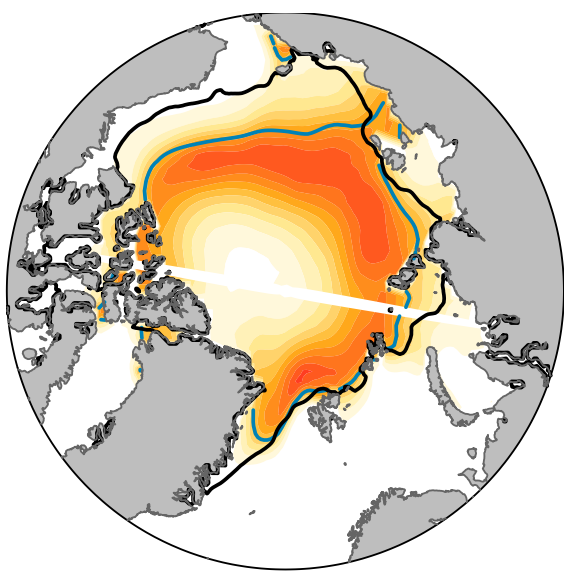

(b) GFDL CM3

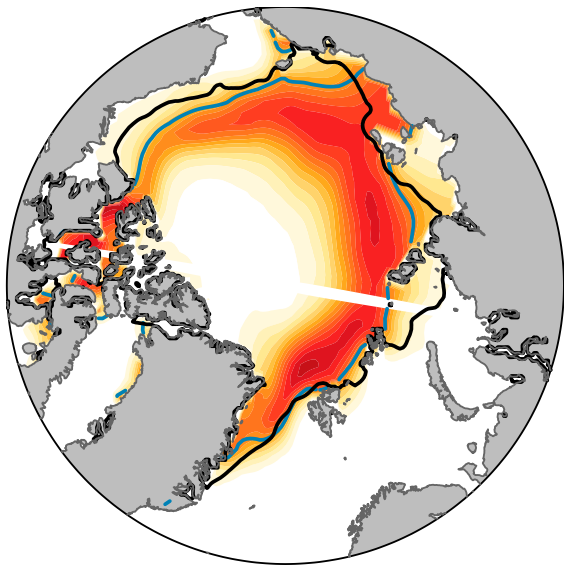

(c) NCAR CESM

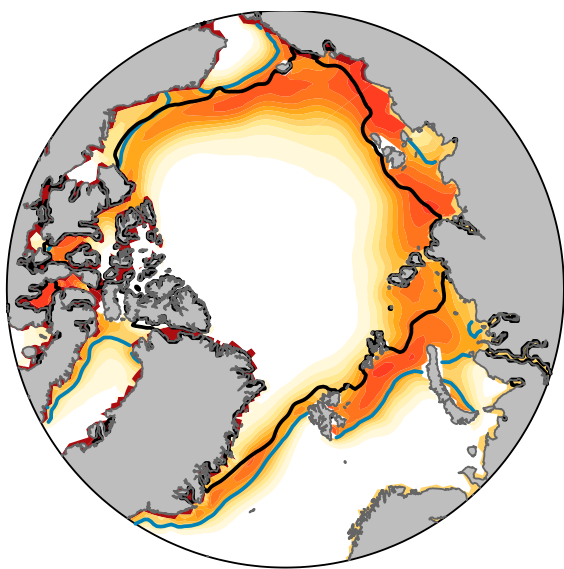

FIG. 4. Comparison of the SD of 30-yr LF simulated September Arctic SIC (\%). Results are from (a) GFDL CM2.1, (b) GFDL CM3, and (c) NCAR CESM. The black lines mark the positions of the observed climatological September sea ice edge (where SIC drops to $15 \%$ ), and the blue lines show the simulated climatological September sea ice edge in each model.
For low-frequency variability, the correlations between $\mathrm{HT}_{\mathrm{ATL}}$ and $\mathrm{AD}$, and between $\mathrm{HT}_{\mathrm{ATL}}$ and $\mathrm{HT}_{\mathrm{PAC}}$, are negligible and not significant for all three models. Thus, $\mathrm{HT}_{\mathrm{ATL}}$ can be considered relatively independent from the other two predictors. The correlation between $\mathrm{HT}_{\mathrm{PAC}}$ and $\mathrm{AD}$ is weak but signifi15 cant $(r=0.27)$ in GFDL CM2.1, marginally significant $(r=0.15)$ in GFDL CM3, and not significant $(r=0.18)$ in NCAR CESM. Thus, $\mathrm{HT}_{\mathrm{PAC}}$ and AD are not completely independent in GFDL models; however, their weak correlation is accounted for in the multiple regression model discussed later.

In all three models, the simulated positive AD pat12 terns have a negative SLP anomaly over the Kara Sea and a positive SLP anomaly over Greenland, which compares well with that observed (Fig. 5). This dipole pattern of SLP anomaly modulates the transpolar ice drift from the Pacific side to the Atlantic side. The dipole pattern also contributes to the SLP difference across the Fram Strait, which strongly affects sea ice export through the strait (Smedsrud et al. 2013, 2017).

At multidecadal-centennial time scales, the 30-yr LF September Arctic SIE anomalies show significant anticorrelations with the three LF key predictors in all three coupled models, except for the correlation with AD in NCAR CESM (Fig. 6). Following Zhang (2015), we derive a multiple regression model for the LF September Arctic SIE anomalies using the three LF predictors $\left(\mathrm{HT}_{\mathrm{ATL}}, \mathrm{HT}_{\mathrm{PAC}}\right.$, and $\left.\mathrm{AD}\right)$ :

$$
\operatorname{SIE}(t)=\sum_{i} \beta_{i} P_{i}\left(t-\tau_{i}\right)+\varepsilon,
$$

where $\beta_{i}$ (Table 1 , third column) is the multiple regression coefficient, $\tau_{i}$ (Table 1 , second column) is the time lead when the predictor $P_{i}$ has the maximum anticorrelation with September Arctic SIE, $\varepsilon$ is the residual, and $\operatorname{SIE}_{R}(t)=\sum_{i} \beta_{i} P_{i}\left(t-\tau_{i}\right)$ is the reconstructed Arctic SIE based on the multiple regression. The correlations between the simulated September Arctic SIE and its reconstructed counterparts are $r=0.75,0.76$, and 0.60 in GFDL CM2.1, GFDL CM3, and NCAR CESM, respectively.

In regions close to the climatological sea ice edges where the climatological September SIC is low (Fig. 1), we expect the September SIC to be more sensitive to changes in the thermodynamic or wind forcing. This is confirmed by the regression patterns of September SIC on the three key predictors (Fig. 7). As the climatological sea ice edges shift poleward in models with less climatological September SIE (Fig. 1), the locations of the most significant responses in September SIC to the three key predictors also shift with it as expected (Fig. 7). 


\section{Patterns of Arctic Dipole}

(a) GFDL CM2.1

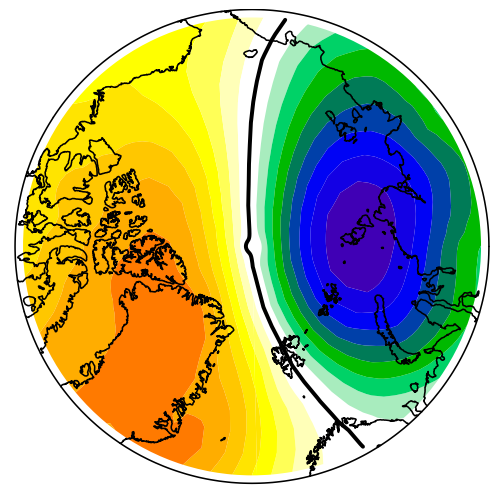

(b) GFDL CM3

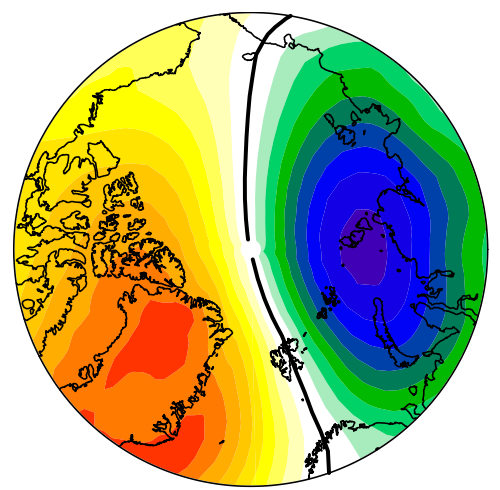

(c) NCAR CESM

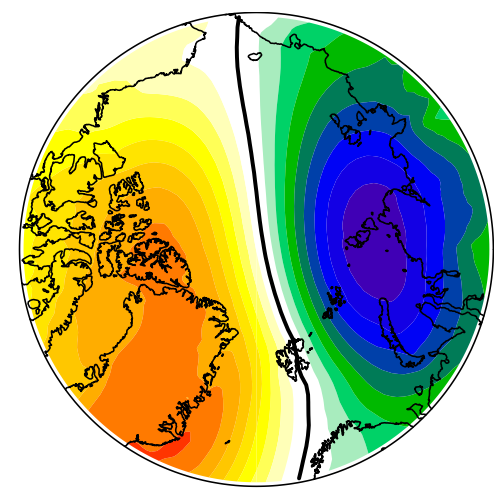

(d) NCEP-NCAR Reanalysis

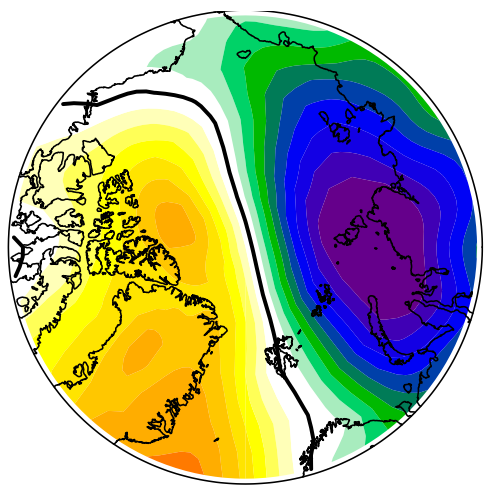

(e) C20 Reanalysis

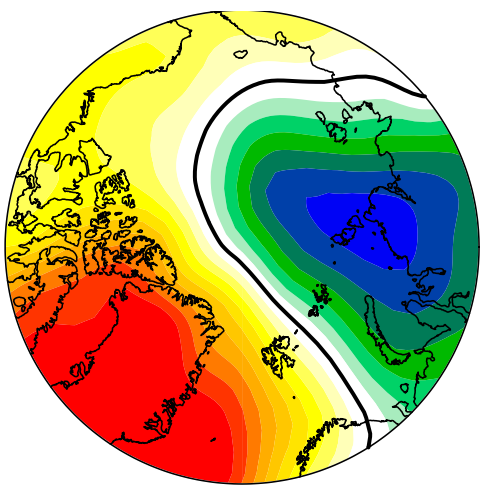

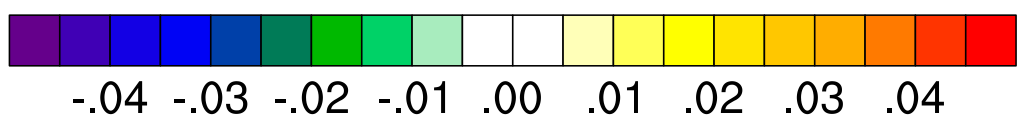

FIG. 5. Spatial patterns of (a)-(c) simulated and (d),(e) observed positive phases of the AD. AD is defined as the EOF2 of the AMJJ SLP anomaly north of the Arctic Circle. The AD pattern is normalized and dimensionless such that the amplitude of AD is carried by the AD index (PC2). To remove the impact of different spatial resolutions on the normalization of the AD pattern, we have the sum of squares for each EOF2 as $N / N_{\mathrm{CM} 2.1}$, that is, the ratio of the total number of grid points within the Arctic Circle $N$ in (a)-(d) to that of GFDL CM2.1 $N_{\mathrm{CM} 2.1}$. Hence, each PC2 is multiplied by $\left(N / N_{\mathrm{CM} 2.1}\right)^{0.5}$. The AD accounts for $10 \%, 9 \%, 9 \%, 13 \%$, and $15 \%$ of the total variance in $(\mathrm{a})-(\mathrm{e})$, respectively. The SDs of unfiltered $\mathrm{AD}$ indices are 37.6, 40.4, 38.0, 31.4, and $32.4 \mathrm{hPa}$ in (a)-(e), respectively, and the SDs of the $30-\mathrm{yr} \mathrm{LF}$ $\mathrm{AD}$ indices are 7.8, 7.6, and $7.7 \mathrm{hPa}$ in (a)-(c), respectively.

The impacts of standardized $\mathrm{HT}_{\mathrm{ATL}}$ and $\mathrm{HT}_{\mathrm{PAC}}$ on September SIE are of the same order, although the standard deviation $(\mathrm{SD})$ of $\mathrm{LF} \mathrm{HT}_{\mathrm{ATL}}(\mathrm{SD}=8.5,6.3$, and $6.4 \mathrm{TW})$ is much larger than that of $\mathrm{LF} \mathrm{HT}_{\mathrm{PAC}}$ $(\mathrm{SD}=0.35,0.62$, and $0.39 \mathrm{TW})$ in all three models. Hence, $\mathrm{HT}_{\mathrm{PAC}}$ appears to be much more efficient in causing low-frequency variability of Arctic summer SIC than $\mathrm{HT}_{\mathrm{ATL}}$. One reason is that the fresher Pacific Water stays on top of the saltier and denser Atlantic Water and has more direct interaction with sea ice. The impact of $\mathrm{HT}_{\mathrm{ATL}}$ on September SIC is important only at multidecadal-centennial time scales so that enough heat carried by the Atlantic inflow can be diffused upward to affect sea ice. In all three models, at low frequency, the $\mathrm{HT}_{\mathrm{ATL}}$ anomaly is affected by the AMOC variability and is significantly correlated with the AMOC index (defined as the maximum annual mean Atlantic overturning streamfunction at $45^{\circ} \mathrm{N}$ ). The $\mathrm{HT}_{\mathrm{PAC}}$ anomaly is influenced by the mean flow advection of temperature anomalies in summer through the Bering Strait and thus is significantly correlated with the summer [AugustOctober (ASO)] Pacific decadal oscillation (PDO) index (defined as the leading mode of summer North Pacific sea surface temperature anomalies north of $20^{\circ} \mathrm{N}$ ). 
(a) GFDL CM2.1
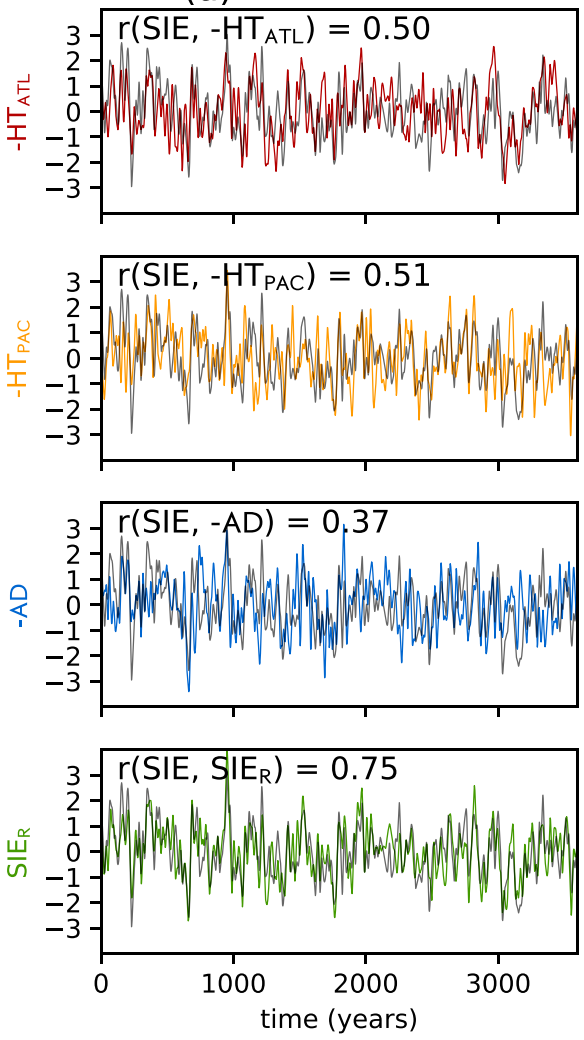

(b) GFDL CM3
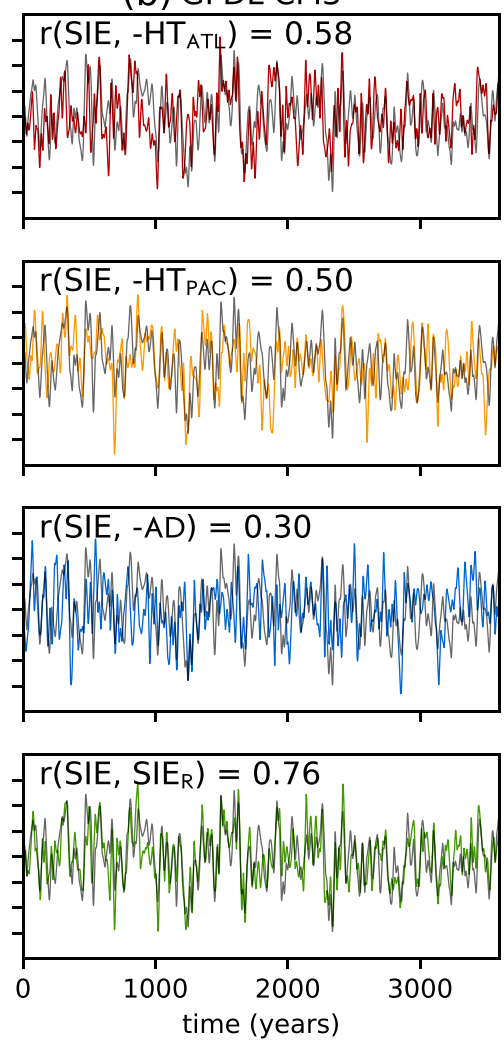

(c) NCAR CESM
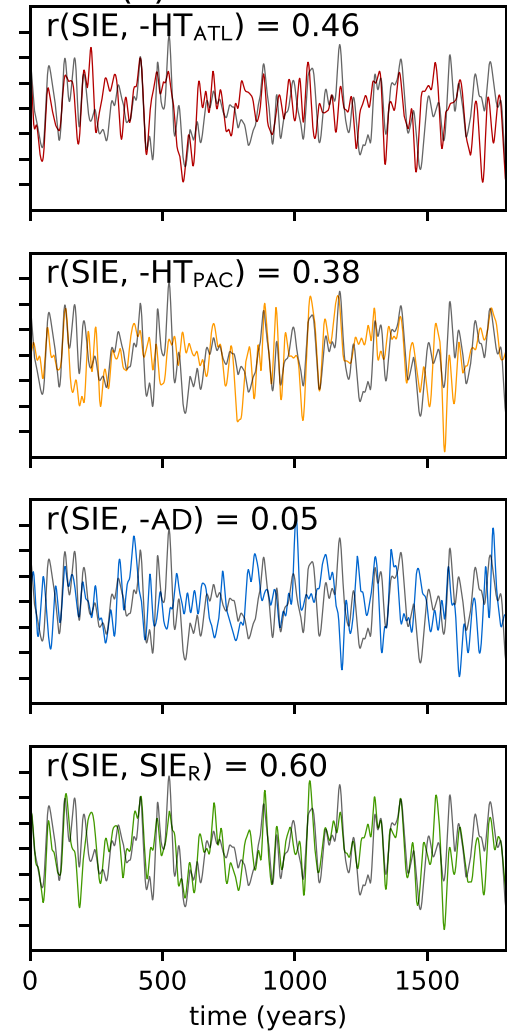

FIG. 6. Multiple regression of September Arctic SIE on three key predictors. The results are shown for (a) GFDL CM2.1, (b) GFDL CM3, and (c) NCAR CESM. For each model, September Arctic SIE (black line) is plotted with (top) inverted annual mean HT $\mathrm{ATL}_{\text {(red }}$ line), (middle top) inverted annual mean $\mathrm{HT}_{\mathrm{PAC}}$ (orange line), (middle bottom) inverted spring AD (blue line), and (bottom) reconstructed September Arctic SIE (green line). All time series are 30-yr LF and normalized by their SDs. The SDs for GFDL CM2.1,

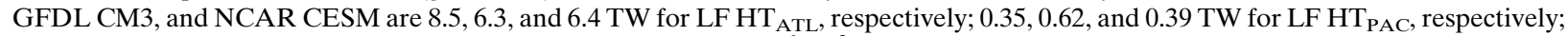
7.8, 7.6, and 7.7 hPa for LF AD, respectively; $0.22,0.35$, and $0.19 \times 10^{6} \mathrm{~km}^{2}$, for simulated LF September Arctic SIE, respectively; and 0.17, 0.26 , and $0.11 \times 10^{6} \mathrm{~km}^{2}$ for reconstructed LF September Arctic SIE, respectively.

Among the three models, the relatively lower correlation between simulated and reconstructed September Arctic SIE in the NCAR CESM is mainly due to the lack of correlation between the AD and September Arctic SIE in this simulation (Fig. 6). However, this does not imply that the AD has no significant impact on summer SIC in NCAR CESM. In all three models, a positive phase of AD leads to a reduction of September SIC on the Pacific side and an increase of September SIC on the Atlantic side by transporting more sea ice from the $\mathrm{Pa}$ cific side to the Atlantic side (Fig. 7, right). In both GFDL CM2.1 and CM3, the increase of SIE on the Atlantic side is less than the reduction on the Pacific side; hence, a positive Arctic dipole leads to a net reduction of the September Arctic SIE.

However, in NCAR CESM as a result of the excessive climatological sea ice and colder mean state on the Atlantic side, the anomalous sea ice exported through the Fram Strait will not be melted but tends to stay in sea ice form, in contrast to the two GFDL models where the anomalous sea ice exported through the Fram Strait is quickly melted. Hence, in NCAR CESM the reduction of SIE on the Pacific side is largely balanced by the expansion of SIE on the Atlantic side, resulting in an insignificant net impact of the Arctic dipole on the September Arctic SIE and thus no correlation between them. The net impact of AD on September Arctic SIE thus depends on the climatological sea ice distribution: it is more efficient in simulations with less climatological summer sea ice on the Atlantic side as in GFDL CM2.1, but it is much less effective in simulations with excessive climatological summer sea ice on the Atlantic side as in NCAR CESM.

The results also suggest that over the satellite period, the response of September Arctic SIE to AD in the real world may be more comparable to that shown in GFDL CM3, since the simulated overall climatological SIC, especially on the Atlantic side, is closer to that observed in GFDL CM3 than in the other two models. The September Arctic SIE variability is more sensitive to the 
TABLE 1. The multiple regression of September Arctic SIE on three key predictors. The second column shows the maximum correlations and the corresponding time leads (yr) between each predictor and September Arctic SIE in parentheses. The third column records the multiple regression coefficients of September Arctic SIE to each predictor.

\begin{tabular}{lcc}
\hline \hline & $\begin{array}{c}\text { Correlation with September } \\
\text { Model } \\
\text { SIE (time lead in yr) }\end{array}$ & Multiple regression \\
\hline \multicolumn{4}{c}{ Atlantic heat transport } \\
CM2.1 & $-0.50(2)$ & $-0.013 \times 10^{6} \mathrm{~km}^{2} \mathrm{TW}^{-1}$ \\
CM3 & $-0.58(6)$ & $-0.029 \times 10^{6} \mathrm{~km}^{2} \mathrm{TW}^{-1}$ \\
CESM & $-0.46(4)$ & $-0.014 \times 10^{6} \mathrm{~km}^{2} \mathrm{TW}^{-1}$ \\
& Pacific heat transport \\
CM2.1 & $-0.51(2)$ & $-0.28 \times 10^{6} \mathrm{~km}^{2} \mathrm{TW}^{-1}$ \\
CM3 & $-0.50(0)$ & $-0.22 \times 10^{6} \mathrm{~km}^{2} \mathrm{TW}^{-1}$ \\
CESM & $-0.38(1)$ & $-0.18 \times 10^{6} \mathrm{~km}^{2} \mathrm{TW}^{-1}$ \\
& Arctic dipole \\
CM2.1 & $-0.37(1)$ & $-0.0067 \times 10^{6} \mathrm{~km}^{2} \mathrm{hPa}^{-1}$ \\
CM3 & $-0.30(0)$ & $-0.010 \times 10^{6} \mathrm{~km}^{2} \mathrm{hPa}^{-1}$ \\
CESM & $-0.05(0)$ & $-0.001 \times 10^{6} \mathrm{~km}^{2} \mathrm{hPa}^{-1}$ \\
\hline
\end{tabular}

$\mathrm{AD}$ in future scenarios with much less September Arctic SIE, and thus much less sea ice on the Atlantic side, than in the past preindustrial scenarios with much more September Arctic SIE. This result is also consistent with a recent modeling study using the NCAR CCSM3 showing that the $\mathrm{AD}$ has an important impact on the September Arctic SIE in the future scenario-driven climate simulations (Wettstein and Deser 2014).

\section{Response of September Arctic surface air temperature to key predictors}

The responses of September Arctic SAT to $\mathrm{HT}_{\mathrm{ATL}}$, $\mathrm{HT}_{\mathrm{PAC}}$, and $\mathrm{AD}$ are largely consistent with the responses of September Arctic SIC (Figs. 7 and 8). Regions with stronger SIC response also show larger anticorrelated SAT change in general, where a decrease in SIC corresponds to an increase in SAT, and vice versa (Fig. 8). A positive $\mathrm{HT}_{\text {ATL }}\left(\mathrm{HT}_{\mathrm{PAC}}\right)$ anomaly accompanies a surface warming over the Arctic, especially over the Atlantic (Pacific) side, and a positive phase of $\mathrm{AD}$ is associated with a surface warming over the Pacific side of the Arctic Ocean, and a surface cooling over the Atlantic side. The results here are consistent with previous studies showing that the Arctic sea ice variability plays a central role in the Arctic SAT variability at the multidecadal time scale (Bengtsson et al. 2004; Serreze et al. 2009; Screen and Simmonds 2010).

Some exceptions to the abovementioned perspective are seen in NCAR CESM, where a positive $\mathrm{HT}_{\mathrm{ATL}}$ anomaly is associated with a surface cooling over the Canadian Arctic Archipelago (Fig. 8c) and a positive $\mathrm{HT}_{\mathrm{PAC}}$ anomaly accompanies a surface cooling near the
Greenland Sea (Fig. 8c). Nevertheless, in both cases SAT indeed varies consistently with anticorrelated SIC changes, which shows minor increases in the cooling regions (Fig. 7c). The surface cooling in both cases is also associated with increased sea ice mass and thickness in the Canadian Arctic Archipelago and in the eastern Greenland Sea (Figs. 9c and 10c).

September Arctic SAT (i.e., averaged September SAT over the Arctic) is strongly correlated with $\mathrm{HT}_{\mathrm{ATL}}$ and $\mathrm{HT}_{\mathrm{PAC}}$ at low frequency. We can build a multiple regression model for September Arctic SAT at low frequency, using $\mathrm{HT}_{\mathrm{ATL}}$ and $\mathrm{HT}_{\mathrm{PAC}}$ as predictors. The correlations between reconstructed and original September Arctic SAT are 0.71 (CM2.1), 0.73 (CM3), and 0.52 (CESM). Adding AD as a predictor to the multiple regression model does not substantially improve the correlations for Arctic-averaged SAT, because the AD's net impact on Arctic SAT is relatively weak as a result of the cancellation of large-scale opposite-signed changes of SAT in the Pacific and the Atlantic sectors (Fig. 8, right). Similar results are also found for annual mean Arctic SAT; that is, we can build a multiple regression model for annual mean Arctic SAT at low frequency, using $\mathrm{HT}_{\mathrm{ATL}}$ and $\mathrm{HT}_{\mathrm{PAC}}$ as predictors. The correlations between reconstructed and original annual mean Arctic SAT are even higher: 0.81 (CM2.1), 0.80 (CM3), and 0.66 (CESM).

\section{Response of Arctic sea ice mass and thickness to key predictors}

All three models show similar patterns of response to the key predictors in summer and winter Arctic SIM (Figs. 9 and 10). At multidecadal-centennial time scales, an enhanced $\mathrm{HT}_{\mathrm{ATL}}$ generally leads to a reduction of summer and winter SIM in the Arctic basin (Figs. 9 and $10)$, with the strongest response in the GreenlandBarents Sea and near the eastern Siberian coast in winter (Fig. 10). Positive anomalies in the $\mathrm{HT}_{\mathrm{PAC}}$ also lead to a reduction in summer and winter SIM (Figs. 9 and 10). The response of SIM is larger on the Pacific side than on the Atlantic side, especially in the winter season (Fig. 10). The response of SIM to a positive phase of AD displays a distinct dipole pattern - a net growth of SIM on the Atlantic side and a net reduction on the Pacific side (Figs. 9 and 10) - consistent with a stronger transpolar ice drift into the Atlantic side. In fact, we can also build a multiple regression model to reconstruct Arctic SIM using the same three predictors and get similar results as for Arctic SIE.

Previous observational-based studies (Jones et al. 1998, 2003; Carmack et al. 2015, 2016) showed that Pacific Water is advected by the ocean circulation to the 


\section{Regressions of September Sea Ice Concentration}

(a)

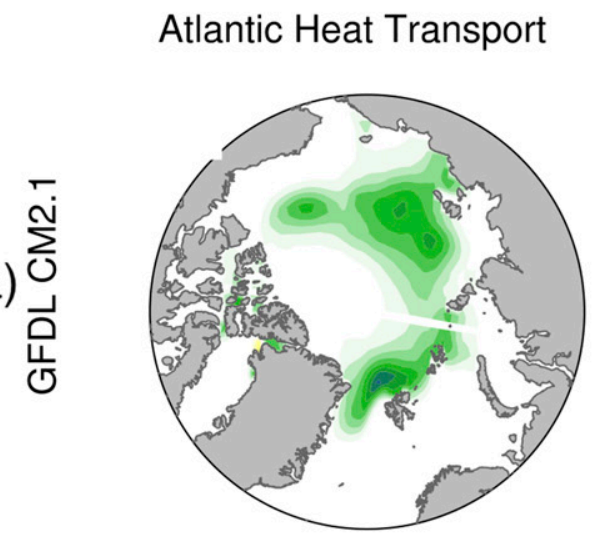

(b) $\frac{\sum_{0}^{m}}{\frac{0}{\mathrm{~L}}}$

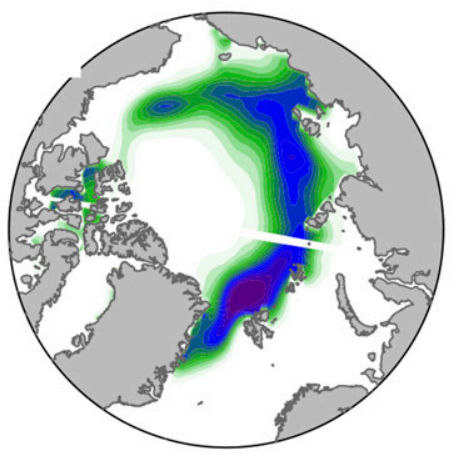

(c)

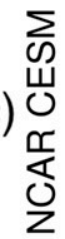

Pacific Heat Transport
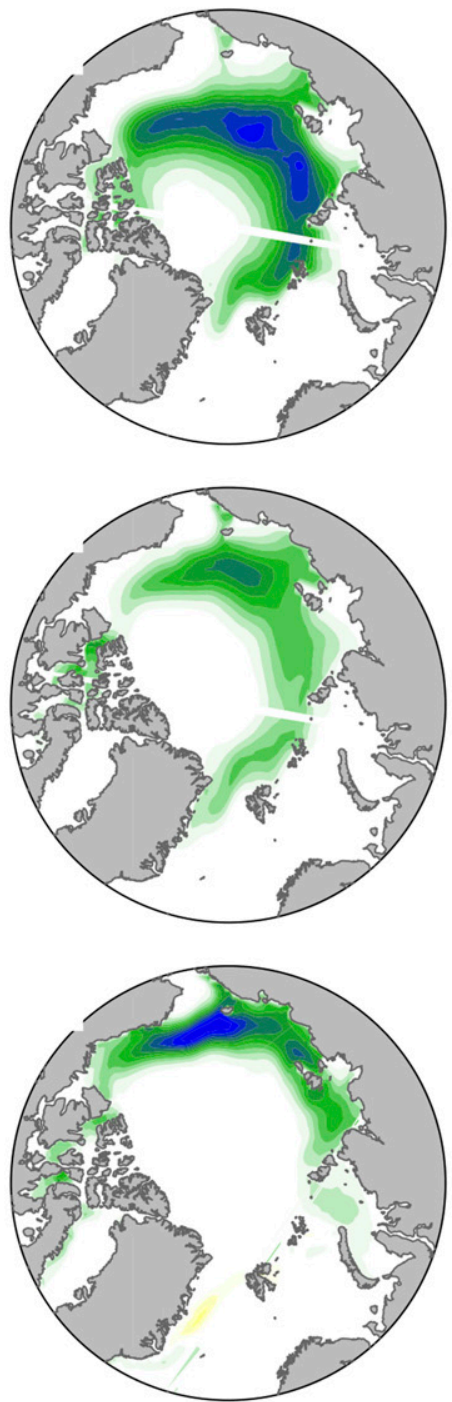

Arctic Dipole
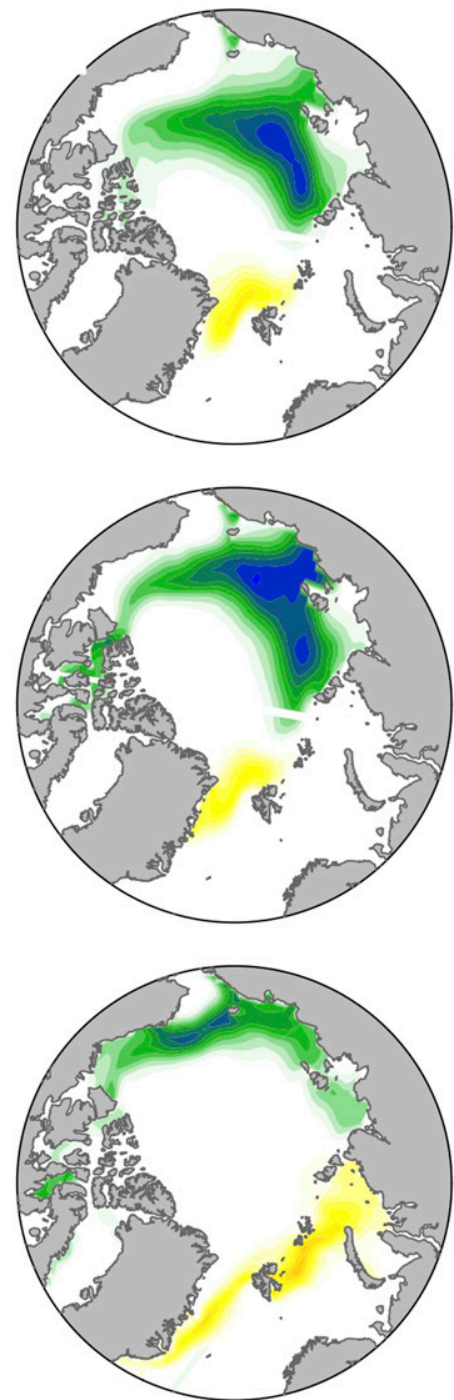

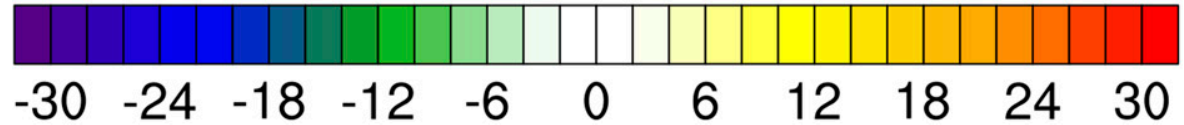

FIG. 7. Regressions of September SIC anomalies. SIC anomalies are regressed on four $\overline{S D}_{\mathrm{s}}$ of (left) $\mathrm{HT}_{\mathrm{ATL}}(28 \mathrm{TW})$, (center) HT $\mathrm{PAC}$ (1.8 TW), and (right) AD (31 hPa) for (a) GFDL CM2.1, (b) GFDL CM3, and (c) NCAR CESM. All time series are 30-yr LF prior to regression. Here $\overline{\mathrm{SD}}$ is the averaged SD of each LF predictor of all three models. For each regression, the time lead is the same as that for September Arctic SIE. The original regressions correspond to one SD of each predictor. To link the regression maps to Eq. (1), in which the unit of the SIE anomaly is $10^{6} \mathrm{~km}^{2}$, the regression maps have been normalized by one $\overline{\mathrm{SD}}$ of SIE. In this way, the regression maps represent the SIC anomaly resulting from each predictor among the anomalous SIC associated with every unit $\left(10^{6} \mathrm{~km}^{2}\right)$ of the SIE anomaly. The one $\overline{\mathrm{SD}}$ of SIE of the three models is about $0.25 \times 10^{6} \mathrm{~km}^{2}$; hence, the regression after normalization corresponds to a regression on four $\overline{\mathrm{SD}}$ of each predictor. (The normalization by one $\overline{\mathrm{SD}}$ of SIE is also used in Figs. 8-10.) The white lines in (a) and (b) are due to the polar projection of SIC simulated on tripolar grids in GFDL models. 


\section{Regressions of September Surface Air Temperature}

\section{Atlantic Heat Transport}

(a)

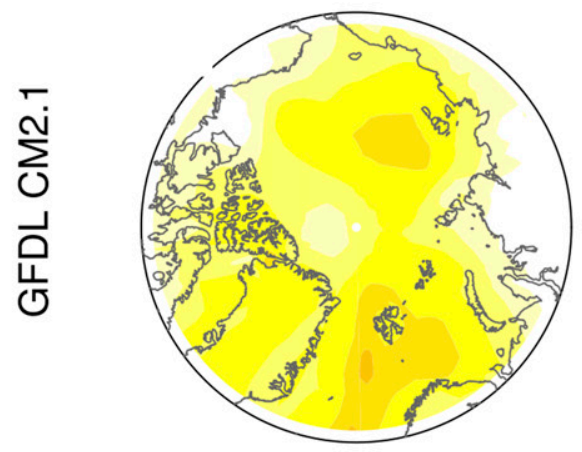

(b)

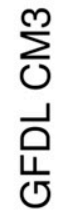

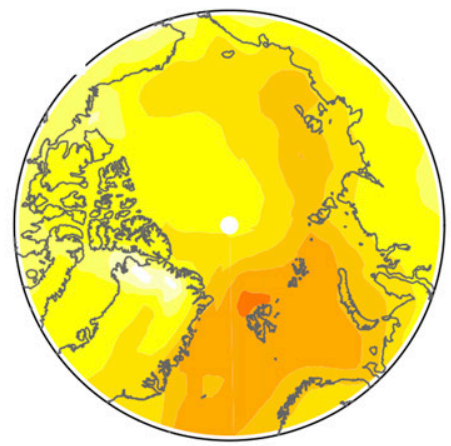

(c)

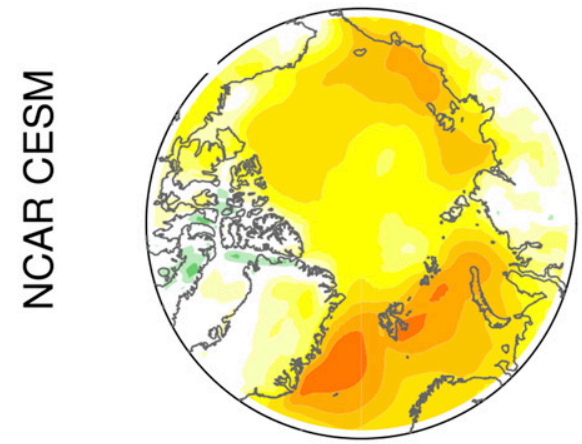

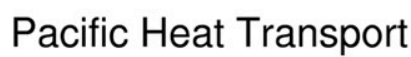
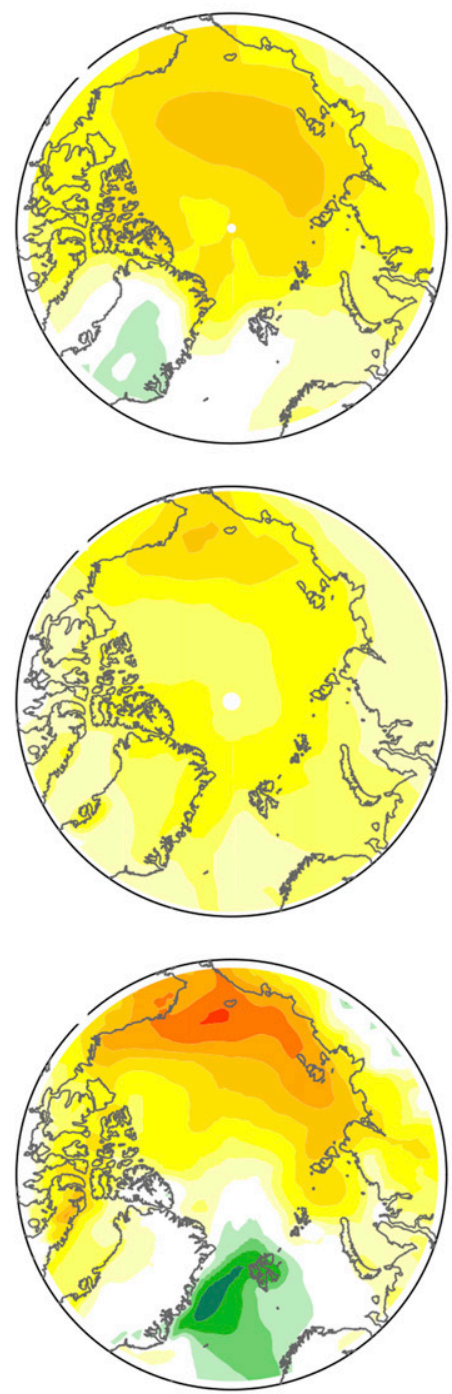

Arctic Dipole
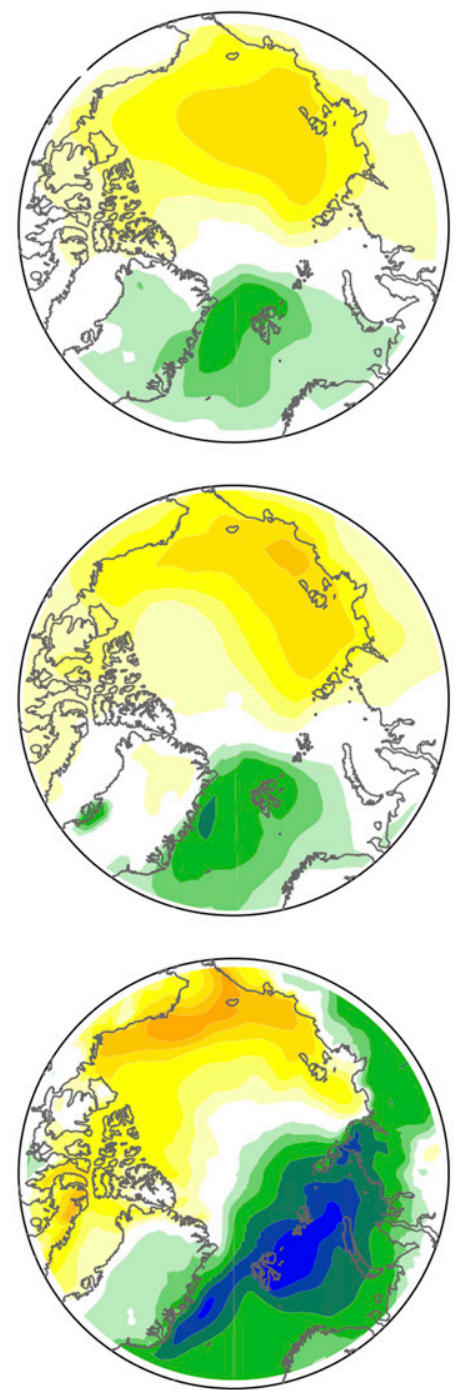

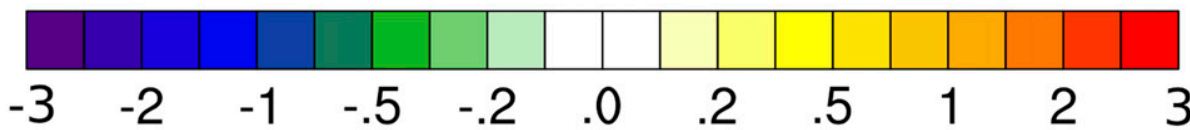

(K)

FIG. 8. As in Fig. 7, but for September SAT (at $2 \mathrm{~m}$ )

Atlantic side (Fram Strait), and Atlantic Water is advected by the ocean circulation into the central Arctic, and can reach the Pacific side (Canadian Basin) and release heat upward (Shimada et al. 2004; Polyakov et al. 2010). Hence, the far-field response of SIM to ocean heat transport can be explained by the ocean circulations in the Arctic basin, which spread the heat carried by the oceanic inflows, inducing net basal melting and the reduction of sea ice thickness in all seasons. The reduction of sea ice thickness in all seasons contributes to the reduction of summer sea ice concentrations in regions close to climatological sea ice edges in the central Arctic, even on the opposite side of the Arctic from the oceanic inflow.

The abovementioned response in SIM to the key predictors largely reflects the response in SIT, which has 


\section{Regressions of September Sea Ice Mass}

\section{Atlantic Heat Transport}

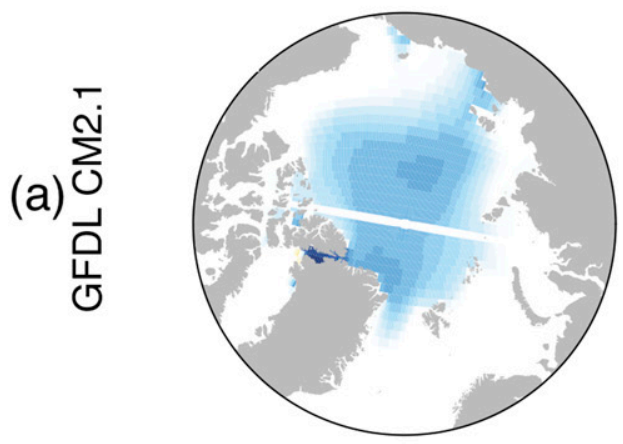

(b)

$\sum_{0}^{m}$

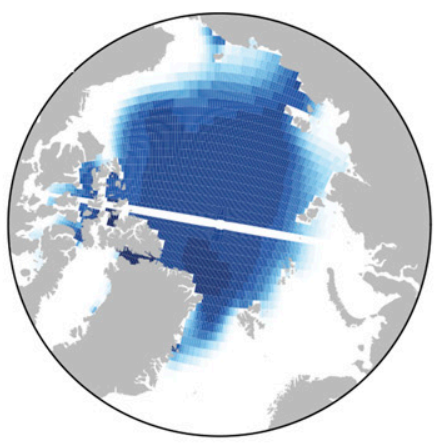

(c)

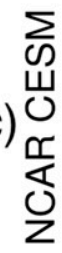

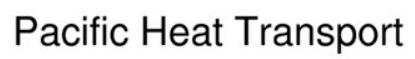
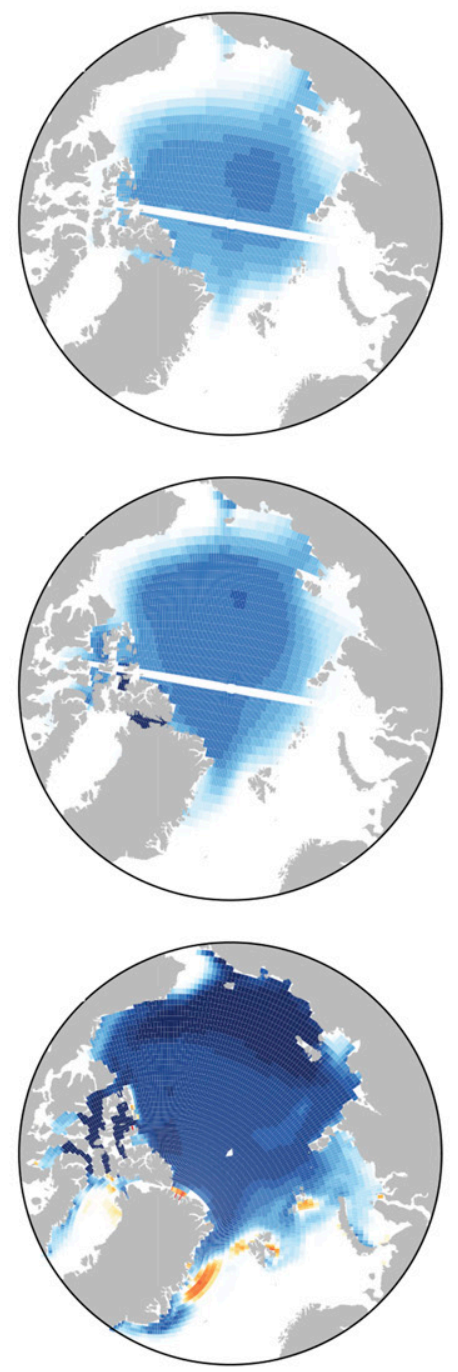

\section{Arctic Dipole}
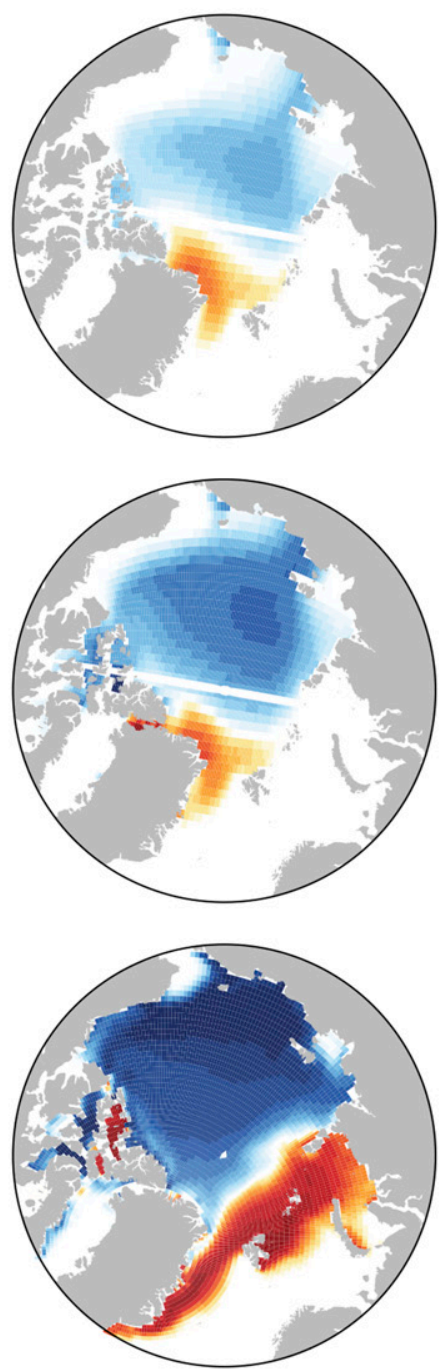

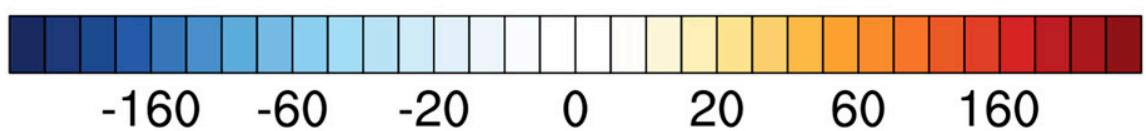

$\left(\mathrm{kg} / \mathrm{m}^{2}\right)$

FIG. 9. As in Fig. 7, but for September SIM. The white lines in (a) and (b) are due to the polar projection of SIM simulated on tripolar grids in GFDL models.

very similar regression patterns (not shown). Comparing the SIM response across the three models, an interesting pattern emerges: models with thicker climatological sea ice (Fig. 2) generally have a stronger response in SIM to the variations in key predictors (Figs. 9 and 10). Among the three models, the responses of SIT and SIM to the anomalous Atlantic or Pacific Ocean heat transport into the Arctic basin are strongest in NCAR CESM, which has the most climatological SIT, and weakest in GFDL CM2.1, which has the least climatological SIT.

The results also support the proposed mechanism that an enhanced ocean heat transport into the Arctic leads to net basal melting and thus a reduction in Arctic ice mass in all seasons (Zhang 2015). With thicker climatological sea ice, the damping effect of the vertical conductive heat flux through the sea ice to the basal oceanic forcing is 


\section{Regressions of March Sea Ice Mass}

\section{Atlantic Heat Transport}

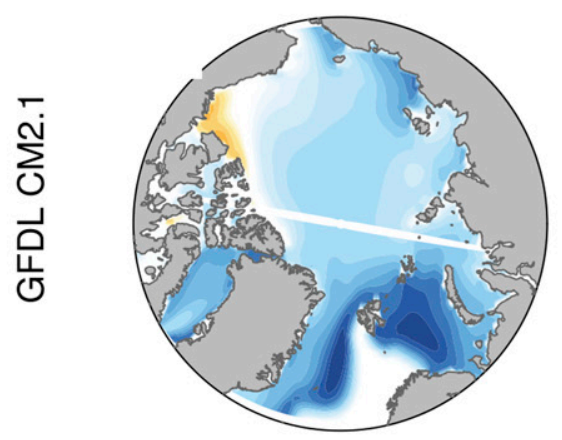

(b)

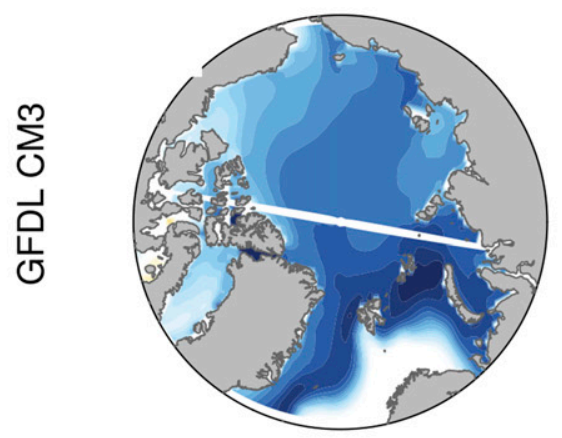

(a)

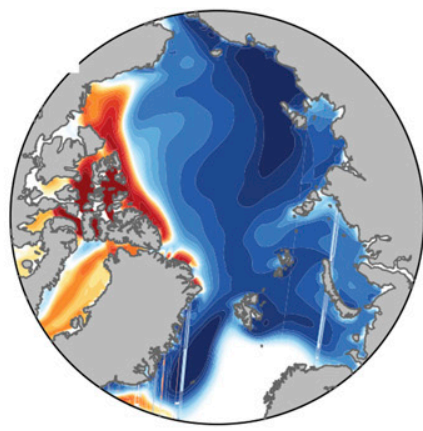

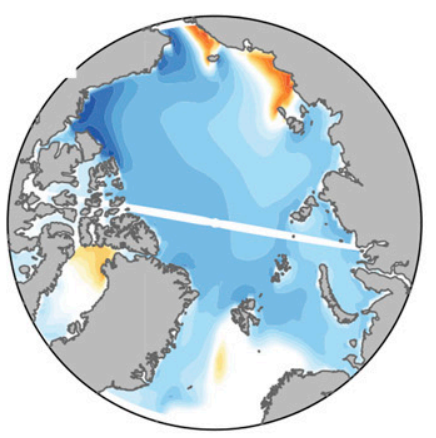

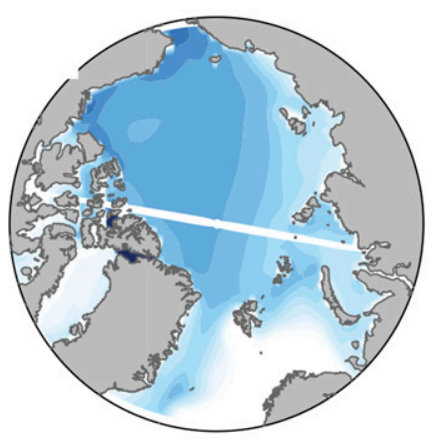

Pacific Heat Transport

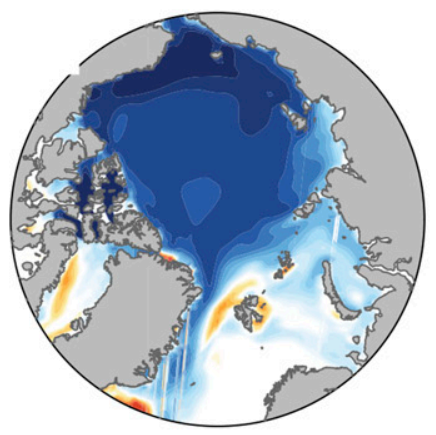

Arctic Dipole
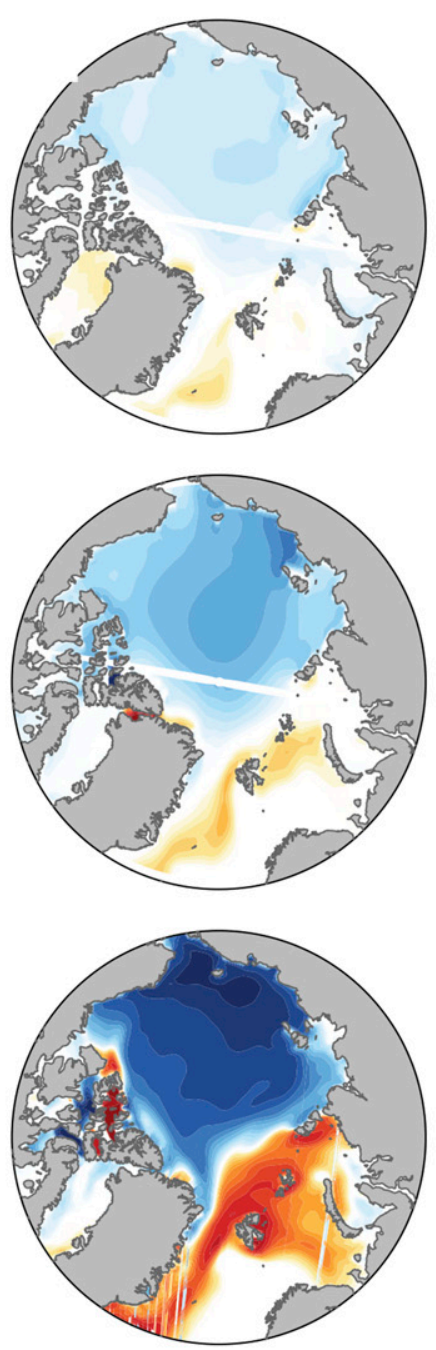

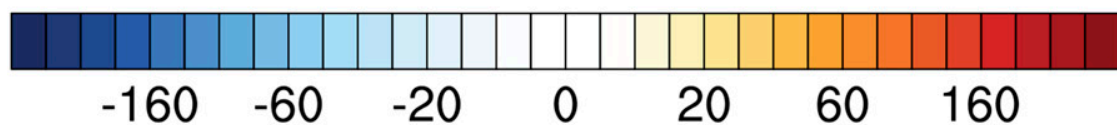

$\left(\mathrm{kg} / \mathrm{m}^{\star \star} 2\right)$

FIG. 10. As in Fig. 7, but for March SIM. The white lines in (a) and (b) are due to the polar projection of SIM simulated on tripolar grids in GFDL models.

weaker, thus the response in SIT has to be stronger so that changes in the damping conductive heat flux can eventually balance changes in the basal oceanic forcing to reach a quasi-equilibrium state. Interestingly, Bitz and Roe (2004) and Holland et al. (2008b) found that the greatest reduction of SIT as a result of the elevated atmospheric $\mathrm{CO}_{2}$ also occurs to the initially thickest sea ice.

The stronger SIM response to AD in models with thicker climatological sea ice (Figs. 9 and 10, right) can be roughly explained from the perspective of the transpolar sea ice mass flux. With larger climatological sea ice thickness $\bar{h}$, under similar anomalous transpolar ice drift $v^{\prime}$ induced by a positive phase of $\mathrm{AD}$, the anomalous transpolar ice mass flux in the central Arctic induced by $\operatorname{AD}\left(v^{\prime} \rho \bar{h}\right.$, where $\rho$ is the density of ice) from the Pacific side to the Atlantic side would be greater, contributing to greater reduction of SIM on the Pacific side and larger increase of SIM on the Atlantic side. 
Hence, it is not surprising to see the strongest response of SIM to AD in the NCAR CESM and the weakest response of SIM to AD in the GFDL CM2.1 among the three models.

The response of SIM and SIT in all seasons contributes to the response of summer SIC and SIE (Zhang 2015). However, the response of summer SIC and SIE to all key predictors is not linearly proportional to the response of SIM and SIT. For example, the response of summer SIC and SIE to $\mathrm{HT}_{\mathrm{ATL}}$ is largest in GFDL CM3 among the three models (Fig. 7 and Table 1). The response of SIM and SIT to $\mathrm{HT}_{\mathrm{ATL}}$ is weakest in GFDL CM2.1, which leads to its weaker response of summer SIC and SIE compared to that in GFDL CM3. On the other hand, although the response of SIM and SIT to $\mathrm{HT}_{\text {ATL }}$ is strongest in NCAR CESM, its very thick climatological sea ice maintains a large gradient in SIM and SIC near the sea ice edge, which reduces the changes in SIC and the shift of sea ice edge in response to changes in SIT. Hence, NCAR CESM displays a weaker response of summer SIC and SIE than GFDL CM3 as result of its thicker climatological sea ice. In this case, the model with intermediate climatological SIT has the largest response in summer SIC and SIE.

Since the majority of $\mathrm{HT}_{\mathrm{ATL}}$ is lost along its pathways to the central Arctic, especially through releasing surface heat flux into the atmosphere and warming the ocean heat content in the Barents Sea, only a very small amount of heat flux anomaly reaches the central Arctic, where it can diffuse across the halocline to affect sea ice. This explains why $\mathrm{HT}_{\text {PAC }}$ anomalies can cause a similar change in sea ice as $\mathrm{HT}_{\mathrm{ATL}}$ even though the amplitude of $\mathrm{HT}_{\mathrm{ATL}}$ is much larger.

At low frequency in a quasi-equilibrium state, the ocean-to-ice heat flux anomaly at the bottom of sea ice in response to changes in $\mathrm{HT}_{\mathrm{ATL}}$ has to be balanced by the anomalous upward heat flux released by the Atlantic Water at the bottom of the halocline (presented in all three models), because the time tendency of the upperocean heat content (over the surface mixed layer and the halocline layer) would be negligible at low frequency. Similarly at low frequency, the total anomalous upward heat flux released by the Atlantic Water at the bottom of the halocline has to be balanced by the anomalous Atlantic heat transport entering the central Arctic. The observed mean Atlantic Water temperature decreases by about $2^{\circ} \mathrm{C}$ from the northern boundary of the Barents Sea to the Canadian coast in the central Arctic, and the exit temperature of the Atlantic Water in the western Fram Strait is also colder than the entering temperature (Polyakov et al. 2010), suggesting the Atlantic Water has lost heat along its pathways in the central Arctic.
At low frequency averaged over the central Arctic domain (defined as the region with greater than $15 \%$ climatological annual mean SIC, that is, within the climatological September sea ice edge), the upper-200-m ocean heat content tendency is negligible compared to the anomalous ocean-to-ice heat flux in all three models (Fig. 11). Therefore, the system is in a quasi-equilibrium state at low frequency, and the anomalous heat released from the ocean to the ice is largely from the anomalous ocean heat transport entering the central Arctic domain (both from the side boundary of the central Arctic domain and from below the permanent halocline within the central Arctic domain).

Figure 12 shows the heat budget averaged over the central Arctic domain, based on the following heat budget equation for sea ice:

$$
-L_{i}\left[\frac{\partial M_{i}}{\partial t}+\nabla \cdot\left(\mathbf{v}_{i} M_{i}\right)\right] \approx F_{o}-F_{\mathrm{SFC}}
$$

Here $M_{i}$ is sea ice mass, $L_{i}$ is the latent heat of fusion of ice, $\mathbf{v}_{i}$ is the sea ice velocity, $F_{o}$ is the ocean-to-ice heat flux, and $F_{\mathrm{SFC}}$ is the net upward surface heat flux. The term $\nabla \cdot\left(\mathbf{v}_{i} M_{i}\right)$ represents ice mass transport divergence. At low frequency, the variance of the tendency term, $-L_{i} \partial M_{i} / \partial t$, is much smaller than that of $F_{o}$ in all three models. Hence, the system is close to a quasiequilibrium state at low frequency, and $F_{o}$ is strongly anticorrelated with $-F_{\mathrm{SFC}}+L_{i} \nabla \cdot\left(\mathbf{v}_{i} M_{i}\right)$ (Fig. 12). The inverted SIM $-M_{i}$ changes with $F_{o}$ (as also shown in Fig. 11) and is out of phase with $-F_{\mathrm{SFC}}+L_{i} \nabla \cdot\left(\mathbf{v}_{i} M_{i}\right)$ (Fig. 12). This means that when the system is close to the quasi-equilibrium state at low frequency, the anomalous $F_{o}$ is the main cause for the Arctic SIM variations [i.e., Arctic SIM decreases (increases) with increased (decreased) ocean-to-ice heat flux], whereas the net downward surface heat flux $-F_{\mathrm{SFC}}$ term plus the term associated with SIM divergence $L_{i} \nabla \cdot\left(\mathbf{v}_{i} M_{i}\right)$ provide a strong negative feedback (damping) to Arctic SIM variations.

Other atmospheric variables, such as TOA fluxes or SAT anomalies, cannot directly affect Arctic sea ice. If there were any impacts from TOA fluxes or SAT anomalies on Arctic sea ice, they would work only through the anomalous $F_{\mathrm{SFC}}$; that is, $F_{\mathrm{SFC}}$ represents the net atmospheric thermodynamic effect on sea ice and appears in the heat budget equation for sea ice [Eq. (2)]. At low frequency, the system is close to a quasiequilibrium state (Fig. 12). If $F_{\mathrm{SFC}}$ were the cause for Arctic SIM variations, then an increased downward surface heat flux $\left(-F_{\mathrm{SFC}}>0\right)$ would be associated with a SIM reduction $\left(-M_{i}>0\right)$, that is, a positive correlation between $-F_{\mathrm{SFC}}$ and $-M_{i}$. Similarly, if changes in SIM 

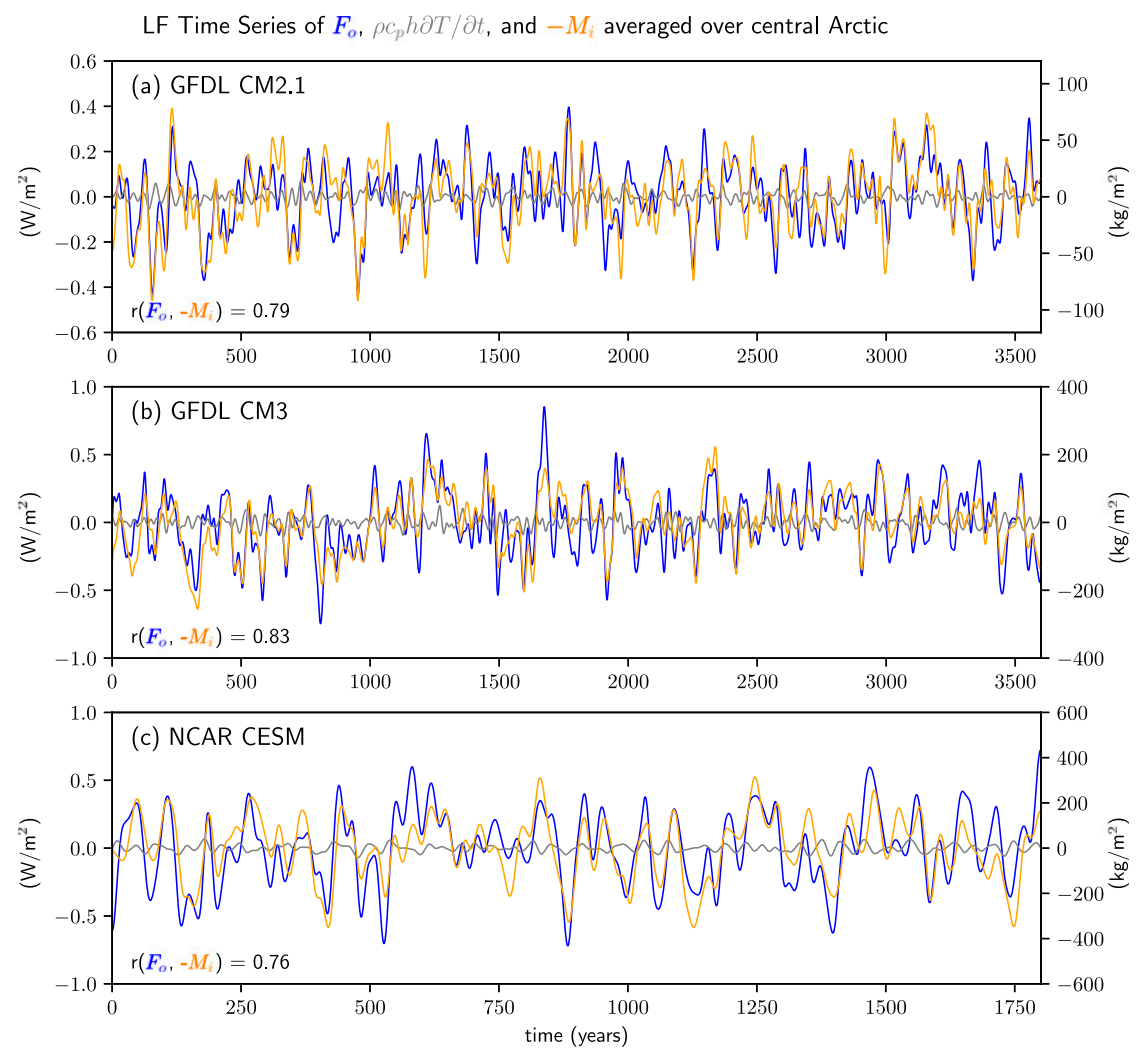

FIG. 11. The 30-yr LF time series of ocean-to-ice heat flux $F_{o}$, upper-200-m ocean heat content tendency $\rho c_{p} h \partial T / \partial t$, and inverted sea ice mass $-M_{i}$. Time series over the entire model period are shown: $3600 \mathrm{yr}$ for GFDL (a) CM2.1 and (b) CM3 and $1800 \mathrm{yr}$ for (c) NCAR CESM. Each term has been averaged over the central Arctic domain (defined as the region with greater than $15 \%$ climatological annual mean SIC, i.e., within the climatological September sea ice edge).

divergence were the cause for Arctic SIM variations, then an increased divergence $\left[L_{i} \nabla \cdot\left(\mathbf{v}_{i} M_{i}\right)>0\right]$ would be associated with a SIM reduction, that is, a positive correlation between $L_{i} \nabla \cdot\left(\mathbf{v}_{i} M_{i}\right)$ and $-M_{i}$. At low frequency, averaged over the central Arctic domain, each of the two individual terms [diagnosed $-F_{\mathrm{SFC}}$ and the term associated with SIM divergence, $\left.L_{i} \nabla \cdot\left(\mathbf{v}_{i} M_{i}\right)\right]$ are of the same order of magnitude as $F_{o}$. However, neither of these two terms has a positive correlation with $-M_{i}$ in any of these three models $[r=-0.19,-0.07$, and -0.71 for $-F_{\mathrm{SFC}}$ and $r=-0.65,-0.87$, and -0.28 for $\left.L_{i} \nabla \cdot\left(\mathbf{v}_{i} M_{i}\right)\right]$. Thus, they have either damping or negligible influences on low-frequency Arctic SIM changes and do not serve as a direct causal factor for these changes.

\section{Linkage between September Arctic SIE and March Barents Sea SIE anomalies}

The Atlantic Water entering the Arctic mainly moves along two pathways-one through the eastern Fram Strait and the other into the Barents Sea through the Barents Sea Opening (BSO) (Årthun et al. 2012). The
Barents Sea usually has the largest SIE in March-April and is almost ice free in September (Smedsrud et al. 2013). Although the recent observed decline of summer Arctic sea ice is mainly on the Pacific side of the Arctic basin, the observed decline of winter Arctic sea ice is most pronounced in the Barents Sea (Årthun et al. 2012; Li et al. 2017). The winter (March) SIE over the Barents Sea has been found to be strongly coupled to the Atlantic heat transport across the BSO ( $\mathrm{HT}_{\mathrm{BSO}}$ ) (Årthun et al. 2012; Smedsrud et al. 2013; Onarheim et al. 2015; Zhang 2015; Li et al. 2017). At low frequency, in all three models, there are strong correlations between $\mathrm{HT}_{\mathrm{ATL}}$ and $\mathrm{HT}_{\mathrm{BSO}}$, with $\mathrm{HT}_{\mathrm{ATL}}$ leading by a few years. The simulated March Barents Sea SIE is strongly anticorrelated with $\mathrm{HT}_{\mathrm{BSO}}$ and lags the anticorrelated $\mathrm{HT}_{\mathrm{ATL}}$ by a few years. Hence, the March Barents Sea SIE could serve as an indicator of the Atlantic heat transport and varies coherently with summer Arctic SIE.

At multidecadal time scales, coherent variations of March Barents Sea SIE and September Arctic SIE are found in all three coupled models, revealing the importance of the Atlantic inflow (Fig. 13). The highest 

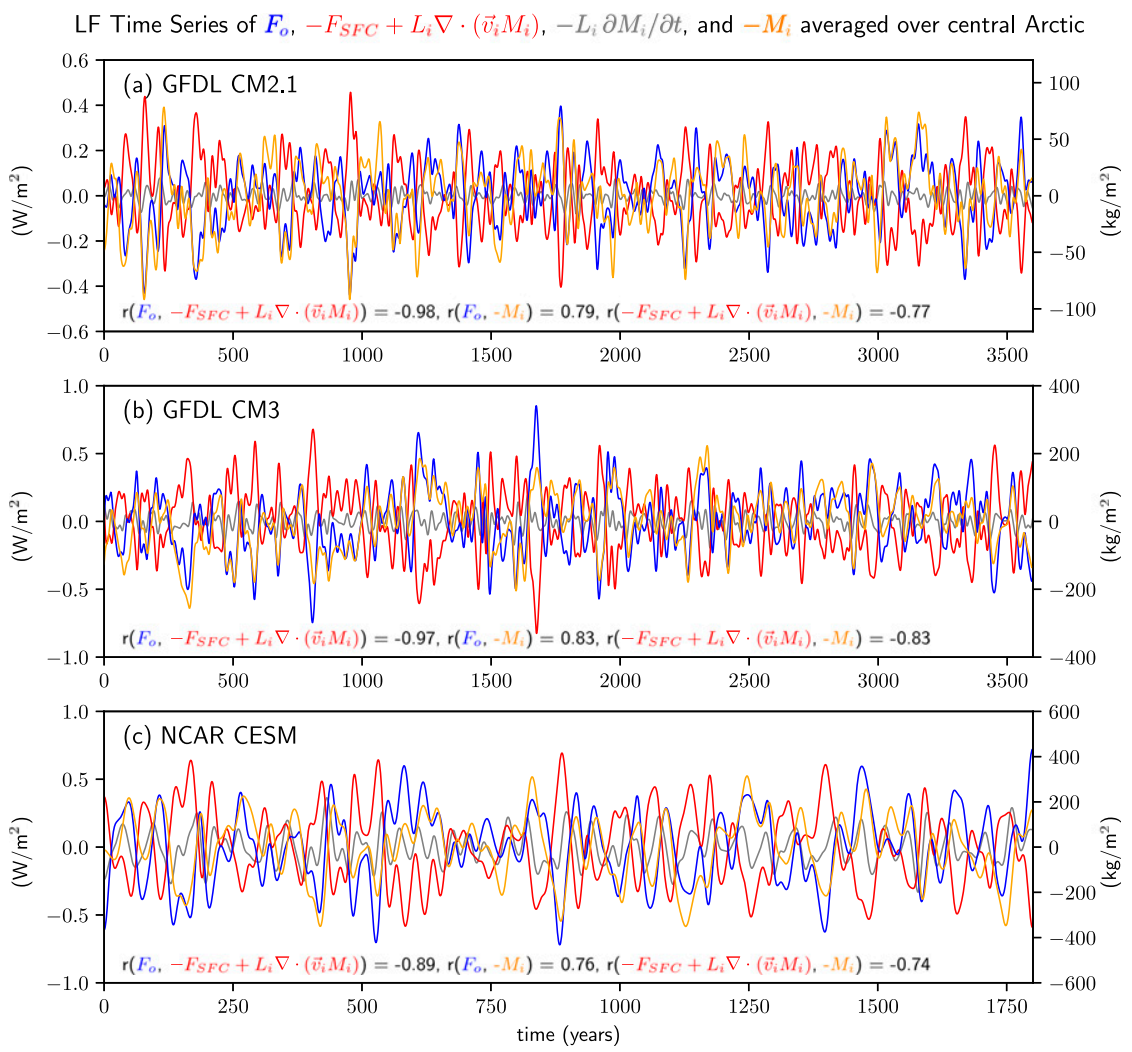

FIG. 12. The 30-yr LF time series of $-L_{i} \partial M_{i} / \partial t, F_{o},-F_{\mathrm{SFC}}+L_{i} \nabla \cdot\left(\mathbf{v}_{i} M_{i}\right)$, and $-M_{i}$. Time series over the entire model period are shown: $3600 \mathrm{yr}$ for GFDL (a) CM2.1 and (b) CM3 and $1800 \mathrm{yr}$ for (c) NCAR CESM. Each term has been averaged over the central Arctic domain. SDs of the first three terms $\left(\mathrm{W} \mathrm{m}^{-2}\right)$ are $0.03,0.14$, and 0.14 for CM2.1; $0.06,0.23$, and 0.23 for CM3; and 0.12, 0.27, and 0.27 for CESM.

correlation is found in GFDL CM3 $(r=0.73)$. Interestingly, the observed March Barents Sea SIE and September Arctic SIE are also highly correlated $(r=0.72$; Fig. 13). The detrended unfiltered observed time series is influenced more by high-frequency variability at the interannual time scale, and the linkage (correlation) between the two variables is much weaker (lower, i.e., $r=0.34)$ at the interannual time scale. The correlation between the undetrended observed time series is higher, because they are both affected by the strong decadalmultidecadal low-frequency decline trends. The coherent changes between March Barents Sea SIE and September Arctic SIE in all three models and observations suggest an important role for enhanced Atlantic inflow in the observed winter and summer Arctic sea ice decline trends over the satellite era.

Within the Arctic Circle, winter Arctic SIE anomalies are mainly due to SIC changes on the Atlantic side (e.g., Barents Sea); hence, at low frequency winter Arctic SIE is strongly anticorrelated with only the Atlantic heat transport, consistent with previous studies (Årthun et al. 2012; Yeager et al. 2015; Li. et al. 2017). The Pacific heat transport and $\mathrm{AD}$ anomalies do not have much impact on winter Arctic SIE, although they can affect winter Arctic sea ice mass (Fig. 10), because within the Arctic Circle the climatological winter SIC is much higher on the Pacific side than on the Atlantic side. In summer, the climatology SIC is also low on the Pacific side, thus summer Arctic SIE is also affected by Pacific heat transport and AD.

\section{Bjerknes compensation}

At multidecadal-centennial time scales, in all three models the $\mathrm{HT}_{\mathrm{PAC}}$ variability is relatively small $(\mathrm{SD}=0.35$, 0.62 , and $0.39 \mathrm{TW})$ and the $\mathrm{HT}_{\mathrm{ATL}}$ variability $(\mathrm{SD}=8.5$, 6.3 , and $6.4 \mathrm{TW}$ ) dominates the zonally integrated poleward ocean heat transport anomalies across the Arctic Circle. A positive $\mathrm{HT}_{\mathrm{ATL}}$ anomaly, typically driven by a stronger AMOC, would cause warming of the Atlantic Water in the Nordic seas and induce a positive $F_{\mathrm{SFC}}$ anomaly in the Arctic domain (Fig. 14). Since the heat capacity of the atmosphere is small and the top-of-theatmosphere (TOA) radiative flux $F_{\mathrm{TOA}}$ is relatively 
September Arctic SIE and March Barents Sea SIE
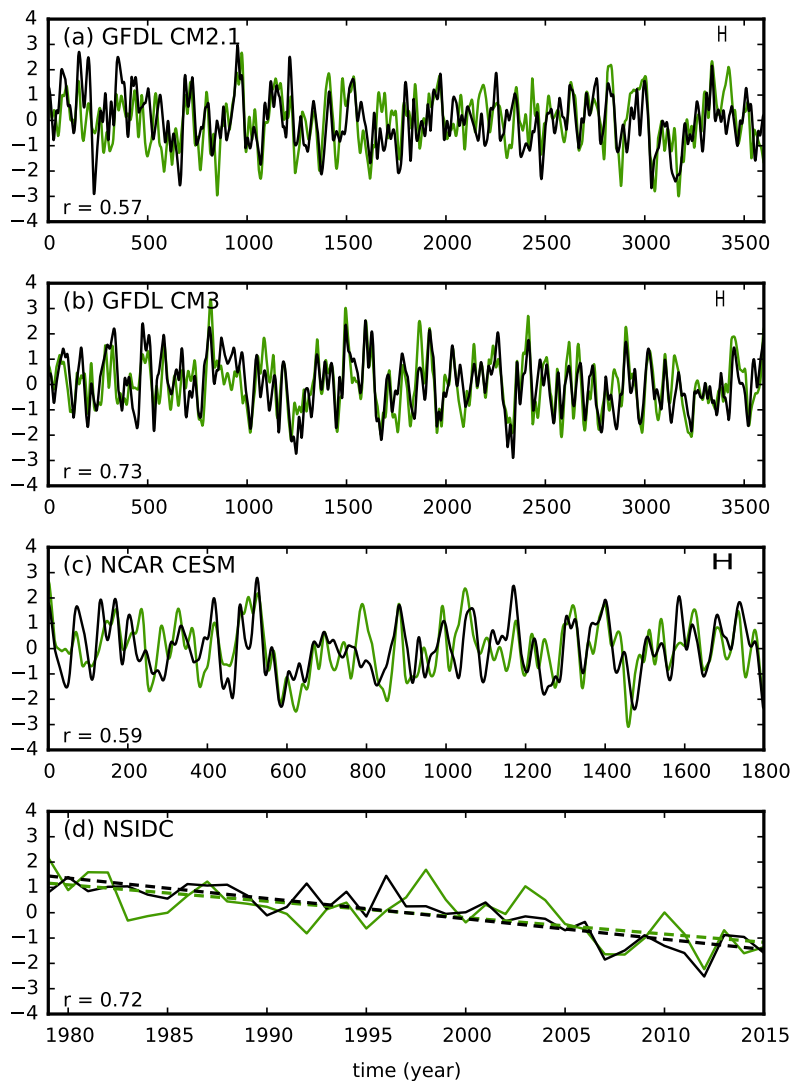

FIG. 13. September Arctic SIE (black lines) and March Barents Sea SIE (green lines) anomalies. Results are from (a) GFDL CM2.1, (b) GFDL CM3, (c) NCAR CESM, and (d) NSIDC (19792015). The scale bar at the top-right corner of (a)-(c) represents the length of observational records $(37 \mathrm{yr})$. All time series are normalized by their SDs, and the simulated SIEs are 30-yr LF, while the observed SIEs are not filtered. The SDs of LF September Arctic SIE are $0.22,0.35$, and $0.19 \times 10^{6} \mathrm{~km}^{2}$, and the SDs of LF March Barents Sea SIE are 0.035, 0.098, and $0.037 \times 10^{6} \mathrm{~km}^{2}$ for GFDL CM2.1, GFDL CM3, and NCAR CESM, respectively. The SDs of the unfiltered observed September and March SIE are 1.08 and $0.148 \times 10^{6} \mathrm{~km}^{2}$, respectively.

insensitive to the surface heating/cooling, the positive upward surface heat flux anomaly is mainly balanced by a reduced zonally integrated poleward atmospheric heat transport into the Arctic ( $\left.\mathrm{HT}_{\mathrm{ATM}}\right)$ (Fig. 14). Here $\mathrm{HT}_{\mathrm{ATM}}$ is calculated as the residual between integrated outgoing TOA flux and $F_{\mathrm{SFC}}$. This method for calculating $\mathrm{HT}_{\mathrm{ATM}}$ has also been used in many previous studies (Shaffrey and Sutton 2006; van der Swaluw et al. 2007; Jungclaus and Koenigk 2010; Farneti and Vallis 2013; Koenigk and Brodeau 2014; Zhang 2015). The anticorrelated relationship between $\mathrm{HT}_{\mathrm{ATM}}$ and $\mathrm{HT}_{\mathrm{ATL}}$ is not trivial (Farneti and Vallis 2013). Only when the TOA flux is insensitive to changes in $F_{\mathrm{SFC}}$ and when the anomalous ocean heat storage is small (i.e., a quasi-equilibrium state so that the anomalous $\mathrm{HT}_{\mathrm{ATL}}$ convergence is close to the anomalous $F_{\mathrm{SFC}}$ ) it is possible to have a strong anticorrelated relationship between $\mathrm{HT}_{\mathrm{ATM}}$ and $\mathrm{HT}_{\mathrm{ATL}}$. From another point of view, the surface warming in the Arctic domain associated with a positive $\mathrm{HT}_{\mathrm{ATL}}$ anomaly reduces the meridional temperature gradient in the atmosphere, which leads to reduced baroclinicity and weaker poleward heat transport by atmospheric transient eddies. This anticorrelation between zonally integrated poleward ocean and atmospheric heat transport anomalies was coined Bjerknes compensation (Bjerknes 1964) and has been found in many previous studies at the decadal time scale (Shaffrey and Sutton 2006; van der Swaluw et al. 2007; Jungclaus and Koenigk 2010; Farneti and Vallis 2013; Koenigk and Brodeau 2014).

At multidecadal-centennial time scales, the $\mathrm{HT}_{\mathrm{ATL}}$ into the Arctic is strongly anticorrelated with the northward $\mathrm{HT}_{\mathrm{ATM}}$ across the Arctic Circle in all three models. This example of Bjerknes compensation in the Arctic region provides a negative feedback to summer Arctic SIE variations in all three models. It serves as another reason why $\mathrm{HT}_{\mathrm{ATL}}$ is relatively inefficient in affecting summer Arctic sea ice variability compared to $\mathrm{HT}_{\mathrm{PAC}}$, in addition to the fact that Pacific Water interacts more directly with sea ice, as discussed in section 3. The modeled Bjerknes compensation is also consistent with previous observation-based studies showing that the atmospheric heat transport into the Arctic region declined (Smedsrud et al. 2008) and that the Atlantic heat transport across the BSO increased over recent decades (Årthun et al. 2012).

\section{Linkage with the observed summer Arctic sea ice decline}

In this section, we estimate the contribution from each predictor to the observed decline in September Arctic SIE, based on the regression coefficients between each predictor and summer Arctic SIE derived from their multidecadal-decadal trends sampled from the models. These estimates are similar to the regression coefficients derived from corresponding LF variables in the models. This is because the multidecadal-decadal trends sampled from the models are an important component of the low-frequency variability. Using the regression coefficients derived from multidecadal-decadal trends instead of those from corresponding LF variables is done for the purpose of comparison with observed trends. There is no direct observational information on $\mathrm{HT}_{\mathrm{ATL}}$. However, other recent studies (Yeager et al. 2015; Li et al. 2017) have inferred that $\mathrm{HT}_{\mathrm{BSO}}$ associated with natural variability has increased by approximately 

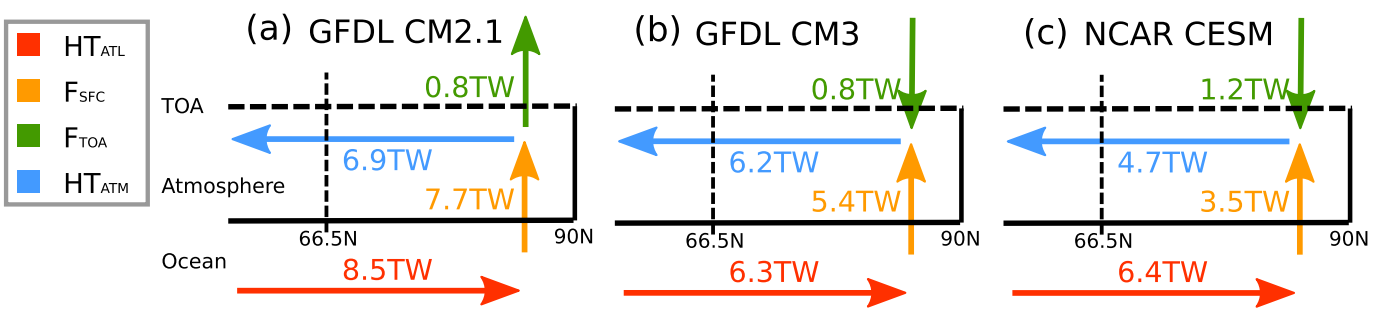

FIG. 14. Schematic diagram illustrating Bjerknes compensation in three models. The poleward $\mathrm{HT}_{\mathrm{ATL}}$ are shown as red arrows, and $\mathrm{HT}_{\mathrm{ATM}}$ are shown as blue arrows. The net upward surface heat fluxes are marked by orange arrows, and the net TOA radiative fluxes are shown as green arrows. The values with the red arrows denote the one

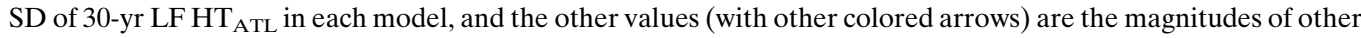
$\mathrm{LF}$ heat fluxes regressed on the corresponding one SD of LF HT $\mathrm{ATL}_{\mathrm{AT}}$. The time leads of 1,3, and $0 \mathrm{yr}$ at the maximum anticorrelations of $r=-0.82,-0.72$, and -0.68 between $\mathrm{LF} \mathrm{HT}_{\mathrm{ATL}}$ and $\mathrm{HT}_{\mathrm{ATM}}$ for GFDL CM2.1, GFDL CM3, and NCAR CESM are used for the regressions, respectively.

30 TW during the 37-yr period (1979-2015). The observed $\mathrm{HT}_{\mathrm{PAC}}$ trend for this $37-\mathrm{yr}$ period is unknown, but the observed $\mathrm{HT}_{\mathrm{PAC}}$ increased by $4 \mathrm{TW}$ in a recent 11-yr period (2001-11; Woodgate et al. 2012). We consider that this decadal trend is not likely due to the long-term changes in anthropogenic forcing but more likely due to natural variability. The observed $\mathrm{AD}$ has an increasing trend of $62 \mathrm{hPa}$ for the 37-yr period (19792015), after removing the centennial long-term $A D$ trend derived from the $\mathrm{C} 20$ data, which is negative [i.e., $-29 \mathrm{hPa}$ $(100 \mathrm{yr})^{-1}$, equivalent to $\left.-11 \mathrm{hPa}(37 \mathrm{yr})^{-1}\right]$. The positive AD trend since 1979, which is opposite of the removed long-term negative trend, is more likely due to natural variability.

We sampled all possible 37- and 11-yr segments of the desired periods from the models. Less than $5 \%$ of all sampled 37-yr trends of $\mathrm{HT}_{\mathrm{BSO}}$ and $\mathrm{AD}$ and 11-yr trends of $\mathrm{HT}_{\mathrm{PAC}}$ in the models are comparable in amplitude to the abovementioned estimated observed trends, which we speculate may indicate a deficiency in model simulations of internal variability. For $\mathrm{HT}_{\mathrm{BSO}}$, the analysis of $\mathrm{Li}$ et al. (2017) suggests a common model deficiency in lowfrequency internal variability and the need for model improvements in future studies. Because the models have apparently substantially underestimated the amplitudes of variability of all predictors at low frequency, we use only the regression coefficients between each predictor and September Arctic SIE derived from the models, and then we multiply the abovementioned available estimated observed trends of the predictors with the corresponding regression coefficients to infer the contributions of the predictors to the observed summer Arctic sea ice decline trend.

The contribution of the $\mathrm{HT}_{\mathrm{BSO}}$ trend [30 TW $(37 \mathrm{yr})^{-1}$ ] to the observed September Arctic SIE decline trend over the 37 years $\left(\sim 3.21 \times 10^{6} \mathrm{~km}^{2}\right)$ is estimated to be $1.17(36 \%), 1.32(41 \%)$, and $0.75(23 \%) \times 10^{6} \mathrm{~km}^{2}$ for the GFDL CM2.1, GFDL CM3, and NCAR CESM, respectively. This is based on the modeled regression coefficients between 37-yr September Arctic SIE trends and 37-yr $\mathrm{HT}_{\mathrm{BSO}}$ trends -0.039 (CM2.1), -0.044 (CM3), and $-0.025(\mathrm{CESM}) \times 10^{6} \mathrm{~km}^{2} \mathrm{TW}^{-1}$. The contribution of the AD trend $\left[62 \mathrm{hPa}(37 \mathrm{yr})^{-1}\right]$ to the observed September Arctic SIE decline trend over the 37 years is estimated to be $0.62(19 \%)$ and $0.74(23 \%) \times 10^{6} \mathrm{~km}^{2}$ for GFDL CM2.1 and CM3, respectively (CESM is not used here). This is based on modeled regression coefficients between 37-yr September Arctic SIE trends and 37-yr AD trends -0.010 (CM2.1) and -0.012 $(\mathrm{CM} 3) \times 10^{6} \mathrm{~km}^{2} \mathrm{hPa}^{-1}$. The contribution of $\mathrm{HT}_{\mathrm{PAC}}$ trend [4 TW $(11 \mathrm{yr})^{-1}$ ] to the observed September Arctic SIE decline trend over 2001-11 $\left(2.13 \times 10^{6} \mathrm{~km}^{2}\right)$ is estimated to be $0.88(41 \%), 0.68(32 \%)$, and 0.56 $(26 \%) \times 10^{6} \mathrm{~km}^{2}$ for the CM2.1, CM3, and CESM, respectively. This is based on modeled regression coefficients between 11-yr September Arctic SIE trends and 11-yr HT PAC $_{\text {trends: }}-0.22$ (CM2.1), -0.17 (CM3), and $-0.14(\mathrm{CESM}) \times 10^{6} \mathrm{~km}^{2} \mathrm{TW}^{-1}$. The abovementioned estimates suggest that natural variability influences via the three predictors could have made substantial contributions to the observed September Arctic SIE decline, although confidently determining the causes of the observed trends in the three predictors requires further study.

\section{Conclusions and discussion}

In this study we investigated the mechanisms for lowfrequency variability of summer Arctic sea ice using available long control simulations from three coupled models: GFDL CM2.1, GFDL CM3, and NCAR CESM. In particular, we focused on the response of lowfrequency summer Arctic sea ice variability to the three previously identified key predictors (Zhang 2015), that is, annual mean northward Atlantic heat transport $\left(\mathrm{HT}_{\mathrm{ATL}}\right)$ and Pacific heat transport $\left(\mathrm{HT}_{\mathrm{PAC}}\right)$ across the 
Arctic Circle and the Arctic dipole (AD). We also examined the influence of the Arctic sea ice mean states on the models' responses. As discussed in Zhang (2015), the three key predictors represent the thermodynamic forcing (Atlantic and Pacific heat transport into the Arctic) and wind forcing over the Arctic region (Arctic dipole) that could have direct causal impacts on summer Arctic sea ice at low frequency.

The simulated Arctic sea ice mean states are quite different in the three coupled models. GFDL CM2.1 simulates less climatological summer SIE, while NCAR CESM simulates more climatological SIE. The simulated climatological summer SIE and SIC in GFDL CM3 lie in between those in GFDL CM2.1 and NCAR CESM. Similarly, the simulated climatological Arctic sea ice mass (SIM) and sea ice thickness (SIT) are least for GFDL CM2.1, most for NCAR CESM, and in between for GFDL CM3.

Despite the very different Arctic sea ice mean states in the three models and the different atmosphere, ocean, and sea ice components, especially between GFDL and NCAR models, there are many robust features in the response of low-frequency summer Arctic sea ice variability to the three key predictors $\left(\mathrm{HT}_{\mathrm{ATL}}, \mathrm{HT}_{\mathrm{PAC}}\right.$, and $\left.\mathrm{AD}\right)$ across all three models. For example, there are significant correlations between the simulated September Arctic SIE and its reconstructed counterpart using a multiple regression model with the three key predictors. The impacts of standardized $\mathrm{HT}_{\mathrm{ATL}}$ and $\mathrm{HT}_{\mathrm{PAC}}$ on September SIE are of the same order, although the amplitude of $\mathrm{HT}_{\mathrm{ATL}}$ lowfrequency variability is much larger than that of $\mathrm{HT}_{\mathrm{PAC}}$. While both are important influences, $\mathrm{HT}_{\mathrm{PAC}}$ is much more efficient in causing low-frequency variability of Arctic summer SIC than $\mathrm{HT}_{\mathrm{ATL}}$. In all models, $\mathrm{HT}_{\mathrm{ATL}}$ is significantly correlated with the AMOC index, and $\mathrm{HT}_{\mathrm{PAC}}$ is significantly correlated with the summer PDO index.

An enhanced $\mathrm{HT}_{\mathrm{ATL}}\left(\mathrm{HT}_{\mathrm{PAC}}\right)$ induces a reduction of summer Arctic SIC and annual mean Arctic SIM and SIT, and a surface warming over the Arctic, especially over the Atlantic (Pacific) sector. A positive phase of $\mathrm{AD}$ induces a reduction of summer Arctic SIC and annual mean SIM and SIT, a surface warming over the Pacific sector, and opposite changes over the Atlantic sector by transporting more ice from the Pacific side to the Atlantic side.

In all three models and the satellite observations, there are significant linkages between March SIE variations over the Barents Sea and September Arctic SIE, suggesting an important role for enhanced Atlantic inflow in both winter and summer Arctic sea ice decline trends over the satellite era.

There is robust Bjerknes compensation at low frequency in all three models; that is, the anomalous
Atlantic heat transport into the Arctic is strongly anticorrelated with the northward atmospheric heat transport across the Arctic Circle at multidecadal-centennial time scales. Thus, the northward atmospheric heat transport across the Arctic Circle provides negative feedback to summer Arctic SIE variations at low frequency in the models.

We also noted interesting aspects of the response of low-frequency summer Arctic sea ice variability, depending on the Arctic sea ice mean states. For example, as the climatological sea ice edges shift poleward in models with less climatological September SIE, the locations of the most significant response in September SIC also shift poleward.

The influence of the AD is more effective in simulations with less climatological summer sea ice on the Atlantic side as in GFDL CM2.1, but it is much less effective in simulations with relatively large amounts of climatological summer sea ice on the Atlantic side as in NCAR CESM. Models with thicker climatological sea ice have a much stronger response in SIM and SIT to the key thermodynamic predictors. Additionally, with thicker climatological sea ice, the transpolar ice mass flux induced by the $\mathrm{AD}$ would be greater, resulting in stronger opposite SIM changes in the Pacific and Atlantic sectors of the central Arctic. Meanwhile, the response of summer SIC and SIE to all key predictors is not linearly proportional to the response of SIM and SIT.

This study also estimated that the three predictors could have made substantial contributions to the observed September Arctic SIE decline. For a more reliable projection of future changes in summer Arctic sea ice, we need to better understand the key mechanisms driving the low-frequency natural variability in summer Arctic sea ice and sustained long-term observations of the key drivers of the low-frequency summer Arctic sea ice variability, such as the Atlantic and Pacific heat transport into the Arctic. If the Atlantic heat transport into the Arctic were to weaken in the near future as a result of multidecadal natural variability, we may see a hiatus or pause in the decline of both winter (Yeager et al. 2015) and summer (Zhang 2015) Arctic SIE.

Acknowledgments. D. Li is funded by the NOAA ESM Initiative. We thank Clara Deser and Adam Phillips for providing access to the NCAR CESM preindustrial control simulation output. The Twentieth Century Reanalysis, version 2, data are provided by NOAA/OAR/ ESRL PSD, Boulder, Colorado (http://www.esrl.noaa. gov/psd). Support for the Twentieth Century Reanalysis project dataset is provided by the U.S. Department of Energy Office of Science Innovative and Novel Computational Impact on Theory and Experiment (DOE 
INCITE) program, and Office of Biological and Environmental Research (BER), and by the National Oceanic and Atmospheric Administration Climate Program Office. We thank Michael Winton and Xiaosong Yang for their valuable comments on a preliminary version of this manuscript.

\section{REFERENCES}

Alexeev, V. A., V. V. Ivanov, R. Kwok, and L. H. Smedsrud, 2013: North Atlantic warming and declining volume of arctic sea ice. Cryosphere Discuss., 7, 245-265, https://doi.org/10.5194/tcd-7245-2013.

Årthun, M., T. Eldevik, L. H. Smedsrud, Ø. Skagseth, and R. B. Ingvaldsen, 2012: Quantifying the influence of Atlantic heat on Barents Sea ice variability and retreat. J. Climate, 25, 4736-4743, https://doi.org/10.1175/JCLI-D-11-00466.1.

Bengtsson, L., V. A. Semenov, and O. M. Johannessen, 2004: The early twentieth-century warming in the Arctic-A possible mechanism. J. Climate, 17, 4045-4057, https://doi.org/10.1175/ 1520-0442(2004)017<4045:TETWIT >2.0.CO;2.

Bitz, C. M., and G. H. Roe, 2004: A mechanism for the high rate of sea ice thinning in the Arctic Ocean. J. Climate, 17, 3623-3632, https:// doi.org/10.1175/1520-0442(2004)017<3623:AMFTHR>2.0.CO;2.

Bjerknes, J., 1964: Atlantic air-sea interaction. Advances in Geophysics, Vol.10, Academic Press, 1-82, https://doi.org/10.1016/ S0065-2687(08)60005-9.

Carmack, E., and Coauthors, 2015: Towards quantifying the increasing role of oceanic heat in sea ice loss in the new Arctic. Bull. Amer. Meteor. Soc., 96, 2079-2105 https://doi.org/ 10.1175/BAMS-D-13-00177.1.

_ , and Coauthors, 2016: Freshwater and its role in the Arctic Marine System: Sources, disposition, storage, export, and physical and biogeochemical consequences in the Arctic and global oceans. J. Geophys. Res. Biogeosci., 121, 675-717, https://doi.org/10.1002/2015JG003140.

Cavalieri, D., C. L. Parkinson, P. Gloersen, and H. J. Zwally, 1996: Sea ice concentrations from Nimbus-7 SMMR and DMSP SSM/ISSMIS passive microwave data, version 1 . Subset used: Northern Hemisphere sea ice concentrations, NASA National Snow and Ice Data Center Distributed Active Archive Center, accessed 4 October 2015, https://doi.org/10.5067/8GQ8LZQVL0VL.

Comiso, J. C., C. L. Parkinson, R. Gersten, and L. Stock, 2008: Accelerated decline in the Arctic sea ice cover. Geophys. Res. Lett., 35, L01703, https://doi.org/10.1029/2007GL031972.

Compo, G. P., and Coauthors, 2011: The Twentieth Century Reanalysis project. Quart. J. Roy. Meteor. Soc., 137, 1-28, https:// doi.org/10.1002/qj.776.

Day, J. J., J. C. Hargreaves, J. D. Annan, and A. Abe-Ouchi, 2012: Sources of multi-decadal variability in Arctic sea ice extent. Environ. Res. Lett., 7, 034011, https://doi.org/10.1088/1748-9326/7/3/034011.

Delworth, T. L., and Coauthors, 2006: GFDL's CM2 global coupled climate models. Part I: Formulation and simulation characteristics. J. Climate, 19, 643-674, https://doi.org/10.1175/JCLI3629.1.

Deser, C., and H. Teng, 2008: Recent trends in Arctic sea ice and the evolving role of atmospheric circulation forcing, 19792007. Arctic Sea Ice Decline: Observations, Projections, Mechanisms, and Implications, Vol. 180, Amer. Geophys. Union, 7-26, https://doi.org/10.1029/180gm03.

Donner, L. J., and Coauthors, 2011: The dynamical core, physical parameterizations, and basic simulation characteristics of the atmospheric component AM3 of the GFDL global coupled model CM3. J. Climate, 24, 3484-3519, https://doi.org/10.1175/ 2011JCLI3955.1.

Farneti, R., and G. K. Vallis, 2013: Meridional energy transport in the coupled atmosphere-ocean system: Compensation and partitioning. J. Climate, 26, 7151-7166, https://doi.org/10.1175/ JCLI-D-12-00133.1.

Francis, J. A., and E. Hunter, 2006: New insight into the disappearing Arctic sea ice. Eos, Trans. Amer. Geophys. Union, 87, 509-511, https://doi.org/10.1029/2006EO460001.

Griffies, S. M., and Coauthors, 2011: The GFDL CM3 coupled climate model: Characteristics of the ocean and sea ice simulations. J. Climate, 24, 3520-3544, https://doi.org/10.1175/ 2011JCLI3964.1.

Halfar, J., W. H. Adey, A. Kronz, S. Hetzinger, E. Edinger, and W. W. Fitzhugh, 2013: Arctic sea-ice decline archived by multicentury annual-resolution record from crustose coralline algal proxy. Proc. Natl. Acad. Sci. USA, 110, 19737-19741, https://doi.org/10.1073/pnas.1313775110.

Holland, M. M., C. M. Bitz, L.-B. Tremblay, and D. A. Bailey, 2008a: The role of natural versus forced change in future rapid summer Arctic ice loss. Arctic Sea Ice Decline: Observations, Projections, Mechanisms, and Implications, Vol. 180, Amer. Geophys. Union, 133-150, https://doi.org/10.1029/180gm10.

, M. C. Serreze, and J. Stroeve, 2008b: The sea ice mass budget of the Arctic and its future change as simulated by coupled climate models. Climate Dyn., 34, 185-200, https://doi.org/ 10.1007/s00382-008-0493-4.

Jones, E. P., L. G. Anderson, and J. H. Swift, 1998: Distribution of Atlantic and Pacific waters in the upper Arctic Ocean: Implications for circulation. Geophys. Res. Lett., 25, 765-768, https://doi.org/10.1029/98GL00464

, J. H. Swift, L. G. Anderson, M. Lipizer, G. Civitarese, K. K. Falkner, G. Kattner, and F. McLaughlin, 2003: Tracing Pacific water in the North Atlantic Ocean. J. Geophys. Res., 108, 3116, https://doi.org/10.1029/2001JC001141.

Jungclaus, J. H., and T. Koenigk, 2010: Low-frequency variability of the Arctic climate: The role of oceanic and atmospheric heat transport variations. Climate Dyn., 34, 265-279, https:// doi.org/10.1007/s00382-009-0569-9.

Kalnay, E., and Coauthors, 1996: The NCEP/NCAR 40-Year Reanalysis Project. Bull. Amer. Meteor. Soc., 77, 437-471, https:// doi.org/10.1175/1520-0477(1996)077<0437:TNYRP>2.0.CO;2.

Kay, J. E., M. M. Holland, and A. Jahn, 2011: Inter-annual to multidecadal Arctic sea ice extent trends in a warming world. Geophys. Res. Lett., 38, L15708, https://doi.org/10.1029/2011GL048008.

— , and Coauthors, 2015: The Community Earth System Model (CESM) Large Ensemble project: A community resource for studying climate change in the presence of internal climate variability. Bull. Amer. Meteor. Soc., 96, 1333-1349, https:// doi.org/10.1175/BAMS-D-13-00255.1.

Koenigk, T., and L. Brodeau, 2014: Ocean heat transport into the Arctic in the twentieth and twenty-first century in EC-Earth. Climate Dyn., 42, 3101-3120, https://doi.org/10.1007/s00382013-1821-x.

Li, D., R. Zhang, and T. R. Knutson, 2017: On the discrepancy between observed and CMIP5 multi-model simulated Barents Sea winter sea ice decline. Nat. Commun., 8, 14991, https://doi. org/10.1038/ncomms14991.

Mahajan, S., R. Zhang, and T. L. Delworth, 2011: Impact of the Atlantic meridional overturning circulation (AMOC) on Arctic surface air temperature and sea ice variability. J. Climate, 24, 6573-6581, https://doi.org/10.1175/2011JCLI4002.1. 
Massonnet, F., T. Fichefet, H. Goosse, C. M. Bitz, G. PhilipponBerthier, M. M. Holland, and P.-Y. Barriat, 2012: Constraining projections of summer Arctic sea ice. Cryosphere, 6, 1383-1394, https://doi.org/10.5194/tc-6-1383-2012.

Miles, M. W., D. V. Divine, T. Furevik, E. Jansen, M. Moros, and A. E. J. Ogilvie, 2014: A signal of persistent Atlantic multidecadal variability in Arctic sea ice. Geophys. Res. Lett., 41, 463-469, https://doi.org/10.1002/2013GL058084.

Onarheim, I. H., T. Eldevik, M. Årthun, R. B. Ingvaldsen, and L. H. Smedsrud, 2015: Skillful prediction of Barents Sea ice cover. Geophys. Res. Lett., 42, 5364-5371, https://doi.org/ 10.1002/2015GL064359.

Overland, J. E., and M. Wang, 2010: Large-scale atmospheric circulation changes are associated with the recent loss of Arctic sea ice. Tellus, 62A, 1-9, https://doi.org/10.1111/j.16000870.2009.00421.x.

- and - 2013: When will the summer Arctic be nearly sea ice free? Geophys. Res. Lett., 40, 2097-2101, https://doi.org/ 10.1002/grl.50316.

_ J. A. Francis, E. Hanna, and M. Wang, 2012: The recent shift in early summer Arctic atmospheric circulation. Geophys. Res. Lett., 39, L19804, https://doi.org/10.1029/2012GL053268.

Perovich, D. K., J. A. Richter-Menge, K. F. Jones, and B. Light, 2008: Sunlight, water, and ice: Extreme Arctic sea ice melt during the summer of 2007. Geophys. Res. Lett., 35, L11501, https://doi.org/10.1029/2008GL034007.

Polyakov, I. V., R. V. Bekryaev, G. V. Alekseev, U. S. Bhatt, R. L. Colony, M. A. Johnson, A. P. Maskshtas, and D. Walsh, 2003: Variability and trends of air temperature and pressure in the maritime Arctic, 1875-2000. J. Climate, 16, 2067-2077, https:// doi.org/10.1175/1520-0442(2003)016<2067:VATOAT>2.0.CO;2.

- , and Coauthors, 2010: Arctic Ocean warming contributes to reduced polar ice cap. J. Phys. Oceanogr., 40, 2743-2756, https://doi.org/10.1175/2010JPO4339.1.

Screen, J. A., and I. Simmonds, 2010: The central role of diminishing sea ice in recent Arctic temperature amplification. Nature, 464, 1334-1337, https://doi.org/10.1038/nature09051.

Semenov, V. A., and L. Bengtsson, 2003: Modes of the wintertime Arctic temperature variability. Geophys. Res. Lett., 30, 1781, https://doi.org/10.1029/2003GL017112.

Serreze, M. C., A. P. Barrett, J. C. Stroeve, D. N. Kindig, and M. M. Holland, 2009: The emergence of surface-based Arctic amplification. Cryosphere, 3, 11-19, https://doi.org/10.5194/tc-3-11-2009.

Shaffrey, L., and R. Sutton, 2006: Bjerknes compensation and the decadal variability of the energy transports in a coupled climate model. J. Climate, 19,1167-1181, https://doi.org/10.1175/ JCLI3652.1.

Shimada, K., F. McLaughlin, E. Carmack, A. Proshutinsky, S. Nishino, and M. Itoh, 2004: Penetration of the 1990s warm temperature anomaly of Atlantic Water in the Canada Basin. Geophys. Res. Lett., 31, L20301, https://doi.org/10.1029/ 2004GL020860.

—, T. Kamoshida, M. Itoh, S. Nishino, E. Carmack, F. McLaughlin, S. Zimmermann, and A. Proshutinsky, 2006: Pacific Ocean inflow: Influence on catastrophic reduction of sea ice cover in the Arctic Ocean. Geophys. Res. Lett., 33, L08605, https://doi.org/10.1029/2005GL025624.

Smedsrud, L. H., A. Sorteberg, and K. Kloster, 2008: Recent and future changes of the Arctic sea-ice cover. Geophys. Res. Lett., 35, L20503, https://doi.org/10.1029/2008GL034813.

, and Coauthors, 2013: The role of the Barents Sea in the Arctic climate system. Rev. Geophys., 51, 415-449, https:// doi.org/10.1002/rog.20017.
M. H. Halvorsen, J. C. Stroeve, R. Zhang, and K. Kloster, 2017: Fram Strait sea ice export variability and September Arctic sea ice extent over the last 80 years. Cryosphere, 11, 6579, https://doi.org/10.5194/tc-11-1-2017.

Steele, M., J. Zhang, and W. Ermold, 2010: Mechanisms of summertime upper Arctic Ocean warming and the effect on sea ice melt. J. Geophys. Res., 115, C11004, https://doi.org/10.1029/ 2009JC005849.

Stroeve, J. C., V. Kattsov, A. Barrett, M. Serreze, T. Pavlova, M. Holland, and W. N. Meier, 2012: Trends in Arctic sea ice extent from CMIP5, CMIP3 and observations. Geophys. Res. Lett., 39, L16502, https://doi.org/10.1029/2012GL052676.

Swart, N. C., J. C. Fyfe, E. Hawkins, J. E. Kay, and A. Jahn, 2015: Influence of internal variability on Arctic sea-ice trends. Nat. Climate Change, 5, 86-89, https://doi.org/10.1038/nclimate2483.

van der Swaluw, E., S. S. Drijfhout, and W. Hazeleger, 2007: Bjerknes compensation at high northern latitudes: The ocean forcing the atmosphere. J. Climate, 20, 6023-6032, https://doi. org/10.1175/2007JCLI1562.1.

Walsh, J. E., F. Fetterer, J. S. Stewart, and W. L. Chapman, 2017: A database for depicting Arctic sea ice variations back to 1850. Geogr. Rev., 107, 89-107, https://doi.org/10.1111/j.1931-0846.2016.12195.x.

Wang, J., J. Zhang, E. Watanabe, M. Ikeda, K. Mizobata, J. E. Walsh, X. Bai, and B. Wu, 2009: Is the Dipole Anomaly a major driver to record lows in Arctic summer sea ice extent? Geophys. Res. Lett., 36, L05706, https://doi.org/10.1029/ 2008 GL036706.

Wettstein, J. J., and C. Deser, 2014: Internal variability in projections of twenty-first-century Arctic sea ice loss: Role of the large-scale atmospheric circulation. J. Climate, 27, 527-550, https://doi.org/10.1175/JCLI-D-12-00839.1.

Winton, M., 2006: Amplified Arctic climate change: What does surface albedo feedback have to do with it? Geophys. Res. Lett., 33, L03701, https://doi.org/10.1029/2005GL025244.

Woodgate, R. A., T. J. Weingartner, and R. Lindsay, 2012: Observed increases in Bering Strait oceanic fluxes from the $\mathrm{Pa}$ cific to the Arctic from 2001 to 2011 and their impacts on the Arctic Ocean water column. Geophys. Res. Lett., 39, L24603, https://doi.org/10.1029/2012GL054092.

Wu, B., J. Wang, and J. E. Walsh, 2006: Dipole anomaly in the winter Arctic atmosphere and its association with sea ice motion. J. Climate, 19, 210-225, https://doi.org/10.1175/JCLI3619.1.

Yeager, S. G., A. Karspeck, and G. Danabasoglu, 2015: Predicted slowdown in the rate of Atlantic sea ice loss. Geophys. Res. Lett., 42, 10 704-10 713, https://doi.org/10.1002/2015GL065364.

Zhang, J., D. A. Rothrock, and M. Steele, 1998: Warming of the Arctic Ocean by a strengthened Atlantic inflow: Model results. Geophys. Res. Lett., 25, 1745-1748, https://doi.org/ 10.1029/98GL01299.

Zhang, R., 2007: Anticorrelated multidecadal variations between surface and subsurface tropical North Atlantic. Geophys. Res. Lett., 34, L12713, https://doi.org/10.1029/2007GL030225.

- 2008: Coherent surface-subsurface fingerprint of the Atlantic meridional overturning circulation. Geophys. Res. Lett., 35, L20705, https://doi.org/10.1029/2008GL035463.

_ 2015: Mechanisms for low-frequency variability of summer Arctic sea ice extent. Proc. Natl. Acad. Sci. USA, 112, 45704575, https://doi.org/10.1073/pnas.1422296112.

, and T. R. Knutson, 2013: The role of global climate change in the extreme low summer Arctic sea ice extent in 2012 [in "Explaining Extreme Events of 2012 from a Climate Perspective"]. Bull. Amer. Meteor. Soc., 94 (9), S23-S26, https:// doi.org/10.1175/BAMS-D-13-00085.1. 